\title{
Reflection of sound from finite-size plane and curved surfaces
}

\section{Rindel, Jens Holger}

Published in:

Journal of the Acoustical Society of America

Publication date:

2005

Link back to DTU Orbit

Citation $(A P A)$ :

Rindel, J. H. (2005). Reflection of sound from finite-size plane and curved surfaces. In Journal of the Acoustical Society of America (Vol. 118/3, pp. 4pAAb3). Acoustical Society of America.

\section{General rights}

Copyright and moral rights for the publications made accessible in the public portal are retained by the authors and/or other copyright owners and it is a condition of accessing publications that users recognise and abide by the legal requirements associated with these rights.

- Users may download and print one copy of any publication from the public portal for the purpose of private study or research.

- You may not further distribute the material or use it for any profit-making activity or commercial gain

- You may freely distribute the URL identifying the publication in the public portal

If you believe that this document breaches copyright please contact us providing details, and we will remove access to the work immediately and investigate your claim. 
$150^{\text {th }}$ Meeting of the Acoustical Society of America Minneapolis, October 17 - 21, 2005

Session "Reflections on Reflections"

\title{
Reflection of sound from finite-size plane and curved surfaces
}

\author{
Jens Holger Rindel \\ Technical University of Denmark \\ jhr@oersted.dtu.dk
}




\section{Outline}

- General model

- Curved reflectors

- Finite size single reflectors

- Array of reflectors

- Conclusion

- Example of application

(Based on work done between 1982 and 1991, but not all has been published) 


\section{General model of sound reflection}

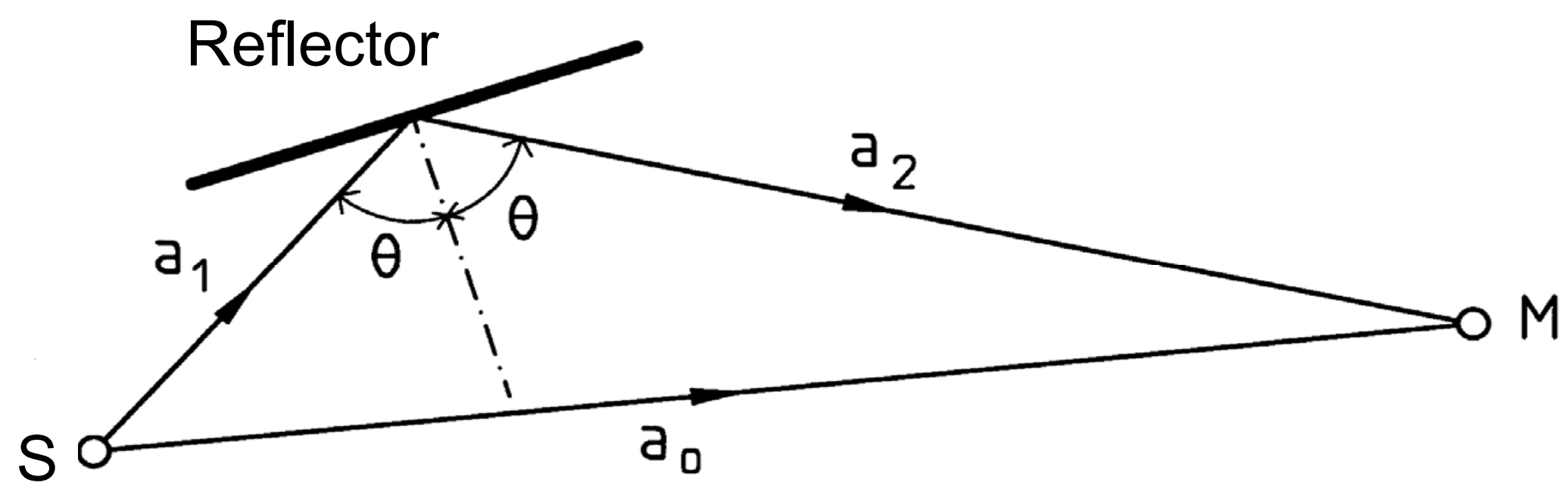

$\Delta \mathrm{L}=\mathrm{L}_{\text {refl }}-\mathrm{L}_{\text {dir }}=\Delta \mathrm{L}_{\mathrm{a}}+\Delta \mathrm{L}_{\mathrm{m}}+\Delta \mathrm{L}_{\mathrm{k}}+\Delta \mathrm{L}_{\mathrm{s}}(\mathrm{dB})$

attenuation from

$\begin{array}{ll}\mathrm{a}: & \text { distance } \\ \mathrm{m}: & \text { absorption (material) } \\ \mathrm{k}: & \text { curvature } \\ \mathrm{s}: & \text { reflector size }\end{array}$




\section{Characteristic distance, $a^{*}$}

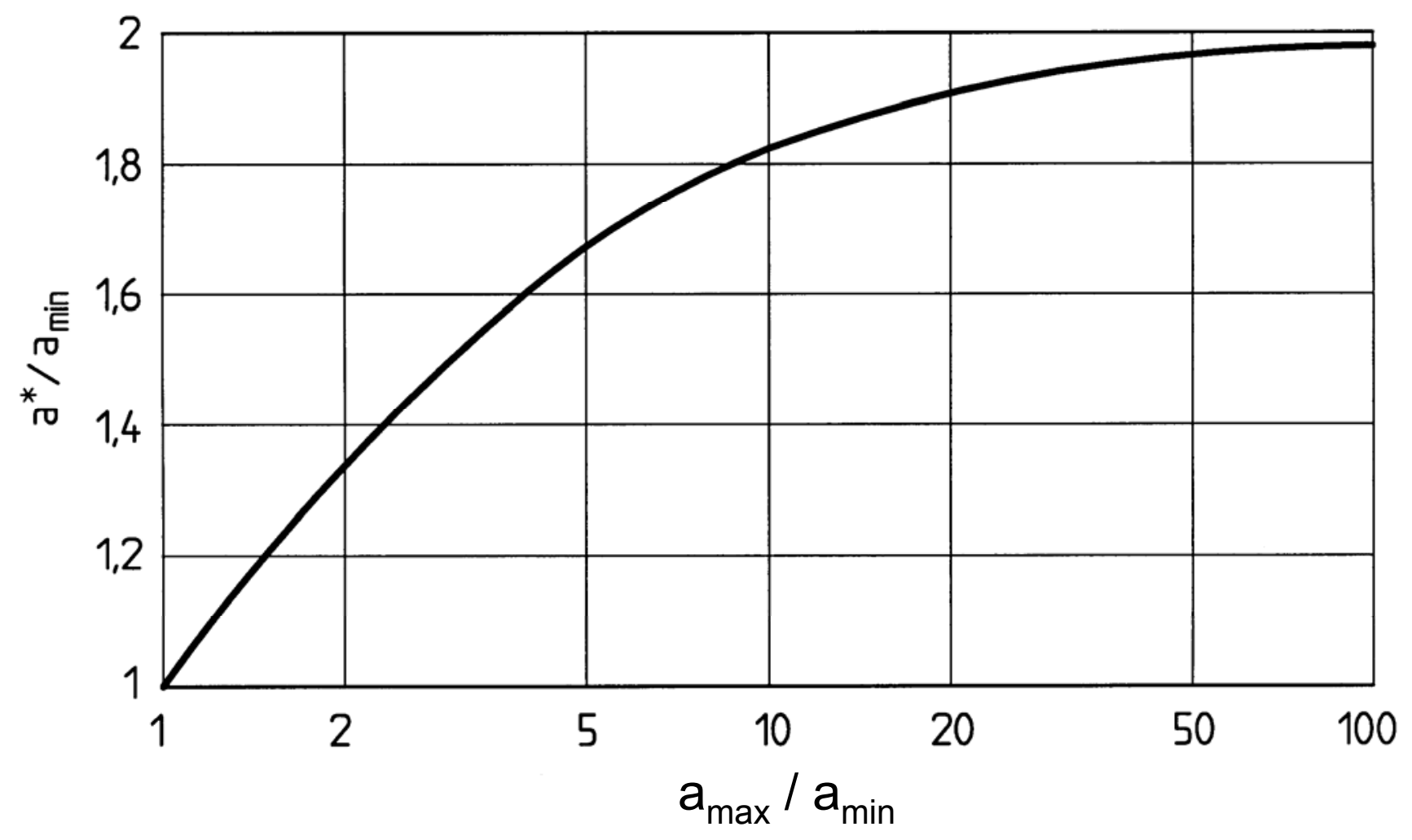

$$
\begin{aligned}
& 1 / a^{*}=\left(1 / a_{1}+1 / a_{2}\right) / 2 \quad \text { (The harmonic average) } \\
& a^{*}=2 a_{1} a_{2} /\left(a_{1}+a_{2}\right)
\end{aligned}
$$




\section{Curved reflectors}

plane

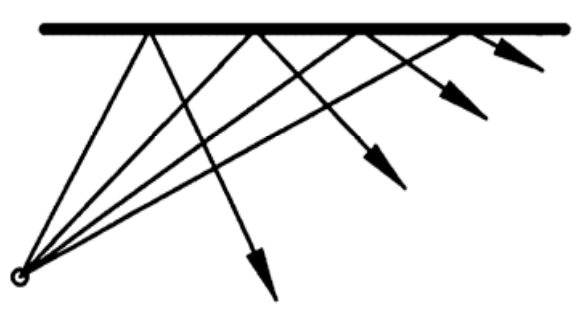

convex

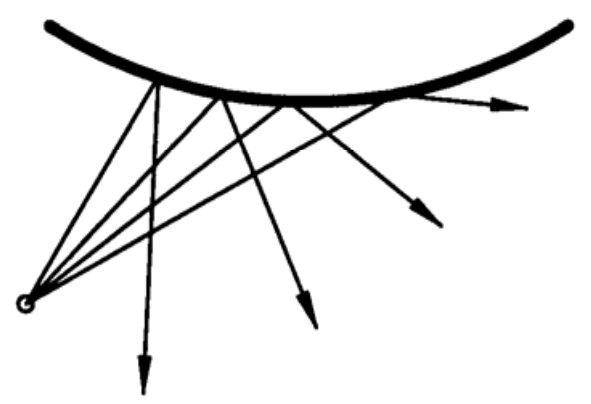

concave

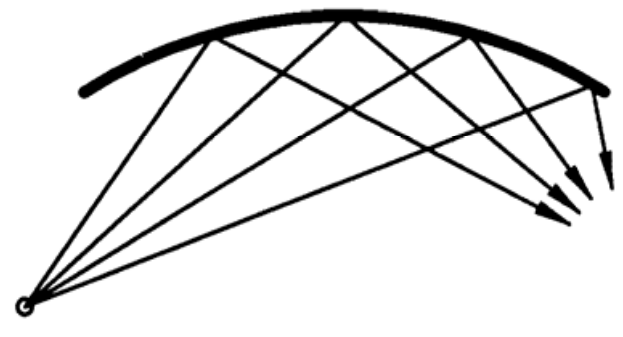

References:

1982: Lydrefleksion fra konvekse og konkave cylinderflader. (In Danish). NAS-82, Stockholm. Proceedings pp. 71-74.

1985: Attenuation of Sound Reflections from Curved Surfaces. 24th Conference on Acoustics, Strbské Pleso. Proceedings pp. 194-197. 


\section{Geometrical analysis}

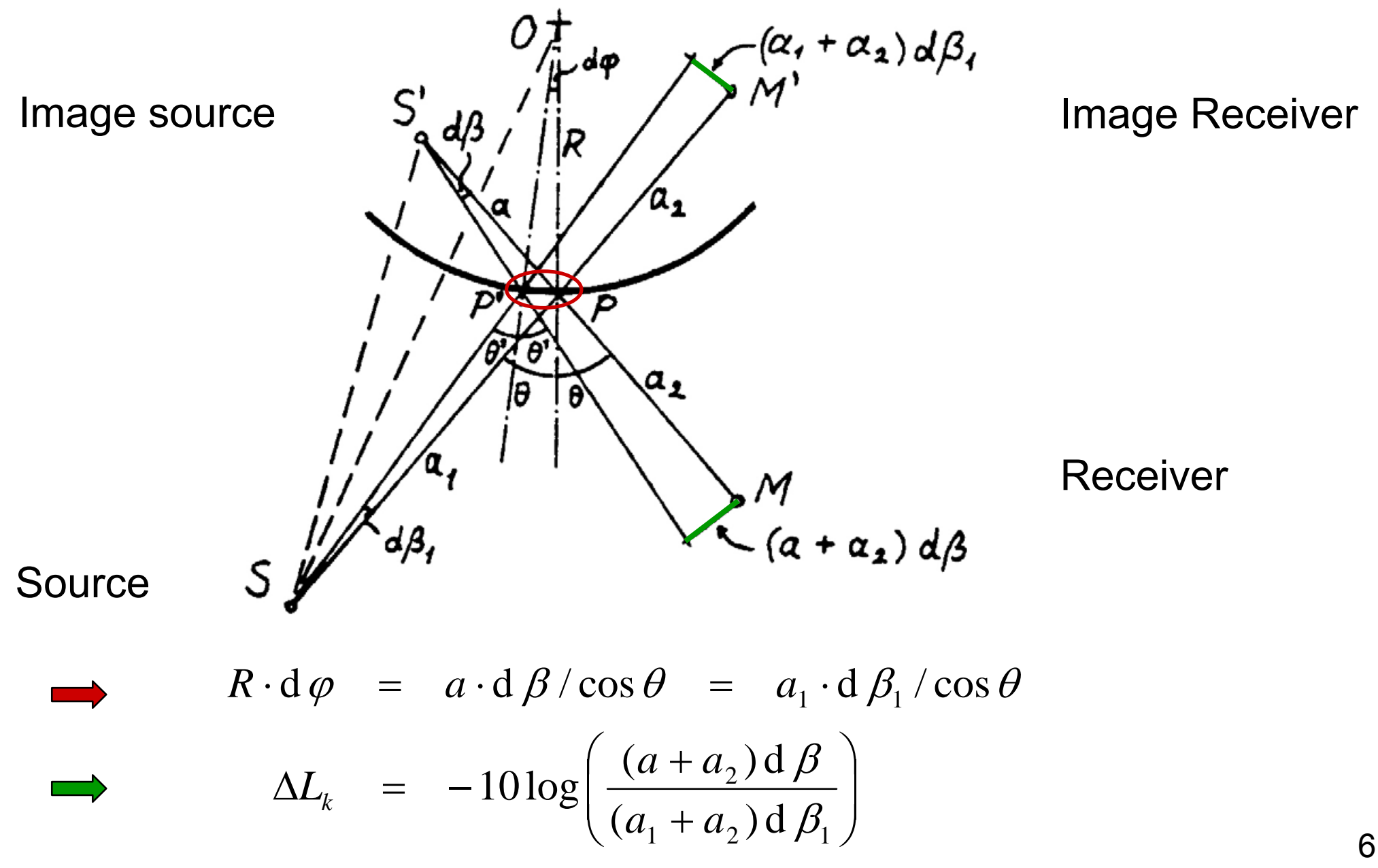




\section{Attenuation due to curvature}

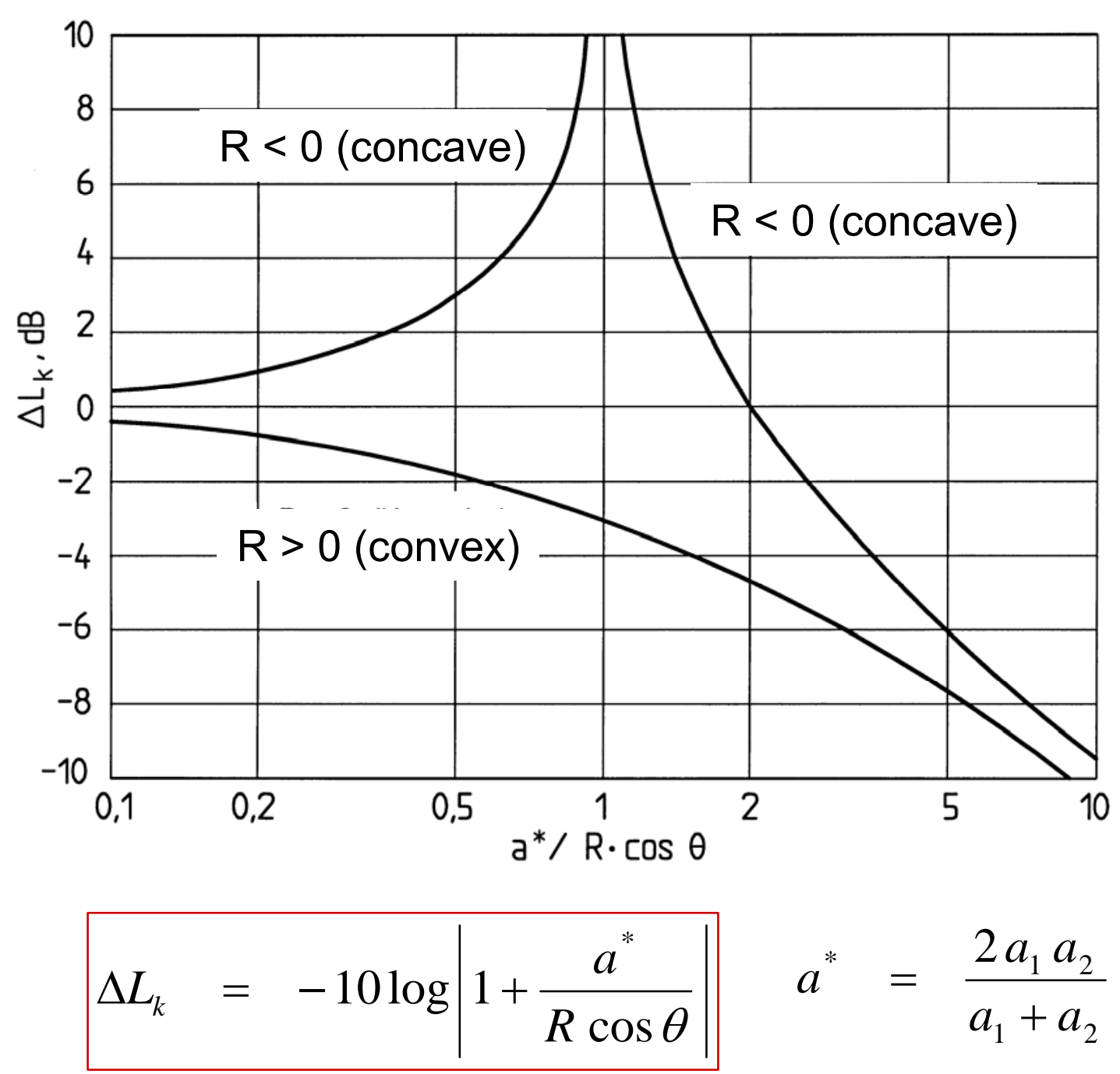




\section{Measurement set-up using TDS technique}

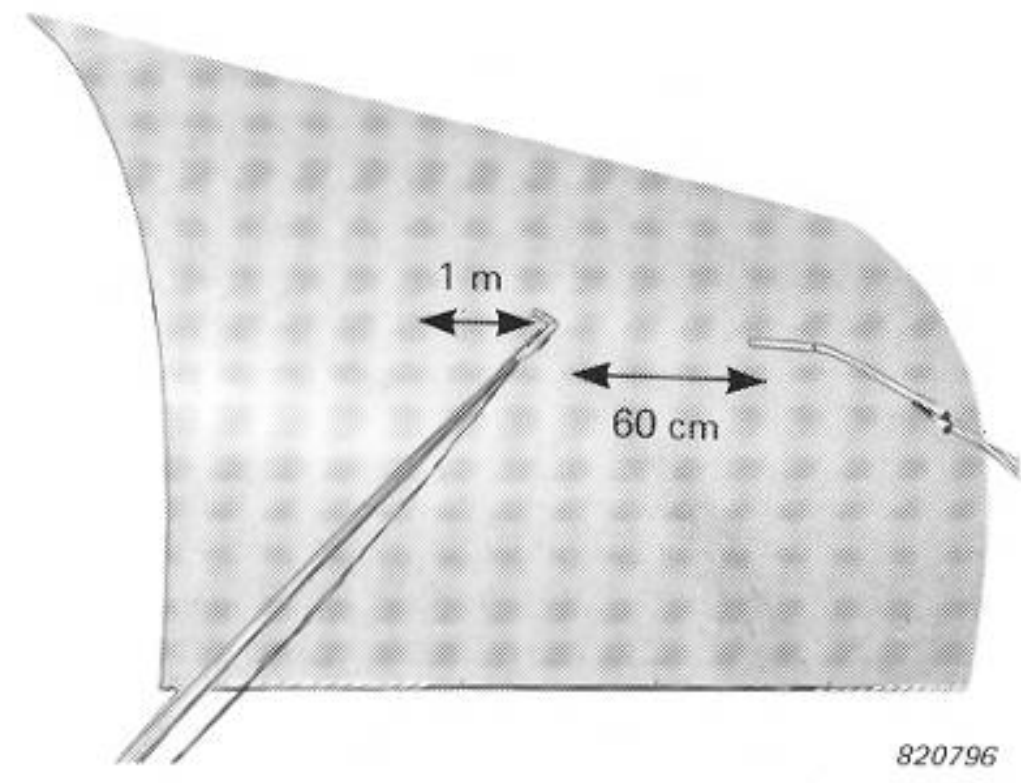

Fig. 6. Convex reflector

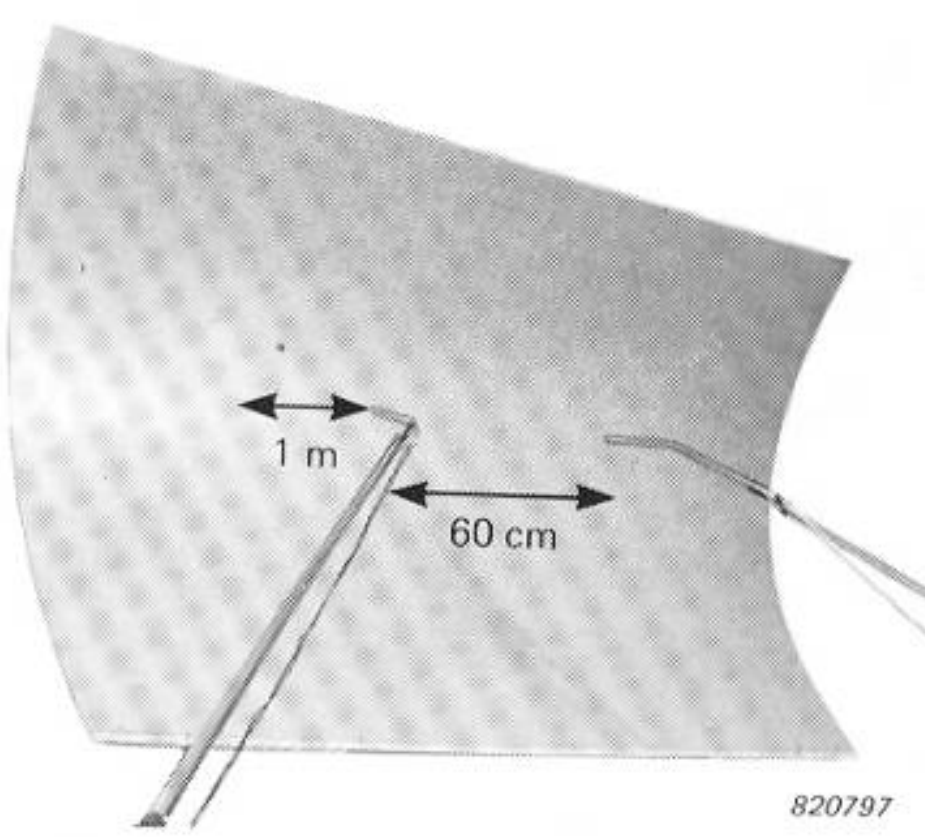

Fig. 7. Concave reflector 


\section{Comparing measured and calculated results}

CALCULATED

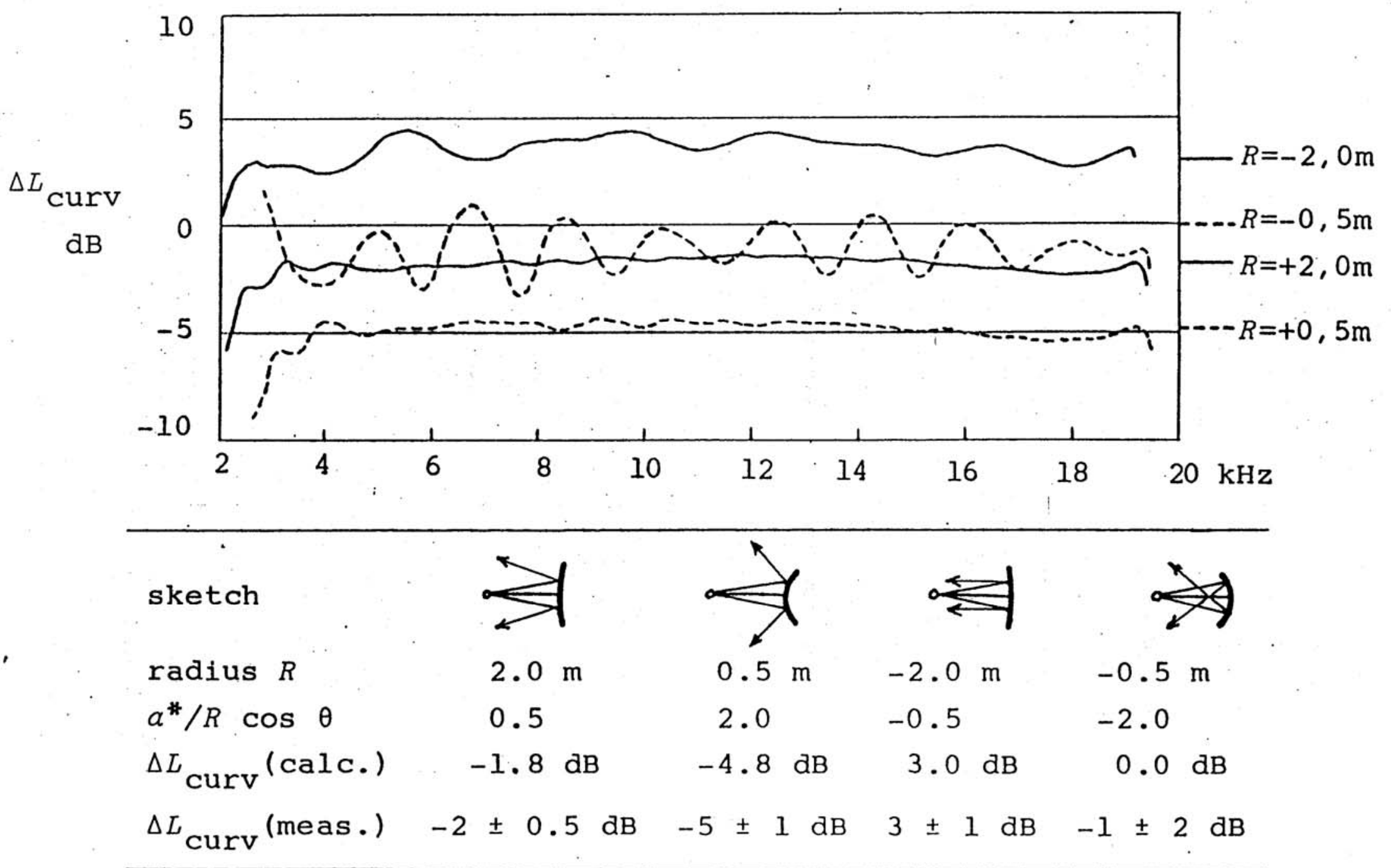




\section{Comments to results on curved reflectors}

- Satisfactory agreement between measurements and theoretical model,

- but diffraction effects are seen as fluctuations in the case of $R=-0.5 \mathrm{~m}$

- so, the finite size should also be taken into account 


\section{Finite size single reflectors}

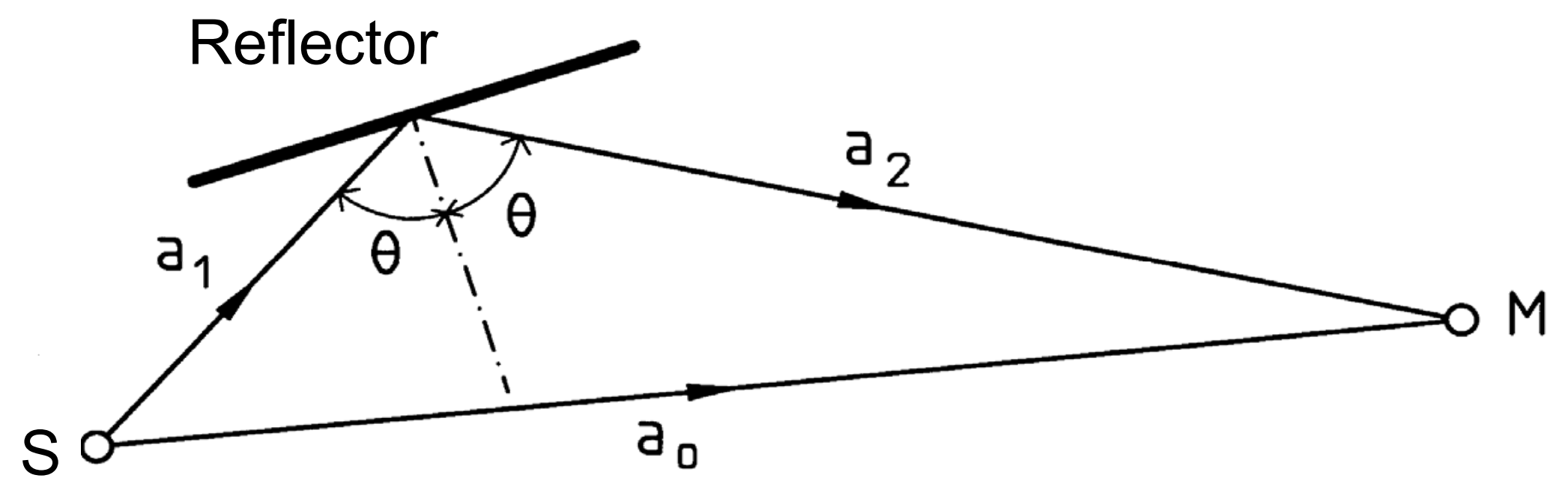

References:

1986: Attenuation of Sound Reflections due to Diffraction. NAM-86, Aalborg.

Proceedings pp. 257-260.

1992: Acoustic Design of Reflectors in Auditoria. Institute of Acoustics, Proceedings, Vol. 14: Part 2, pp.119-128. 


\section{Babinet's Principle}
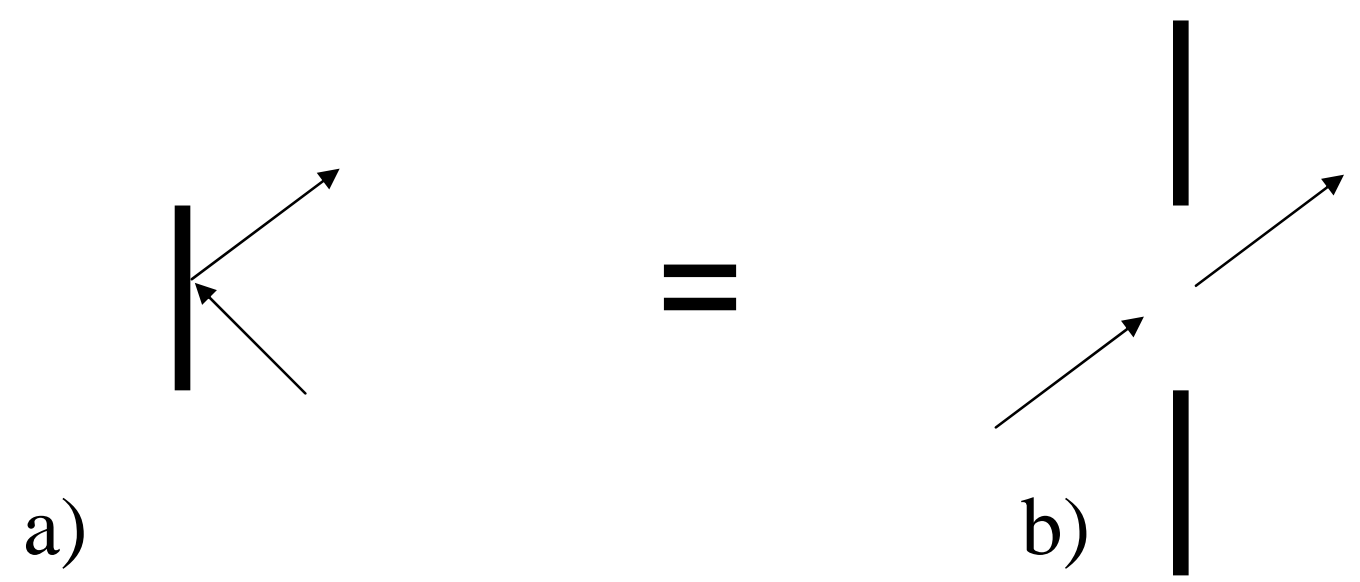

a)

Reflection from a surface (a)

is equivalent to transmission through an aperture (b)

with same size and shape, surrounded by a rigid baffle 


\section{Kirchhoff-Fresnel approximation}

Coordinate system has Origo in the point of geometrical reflection
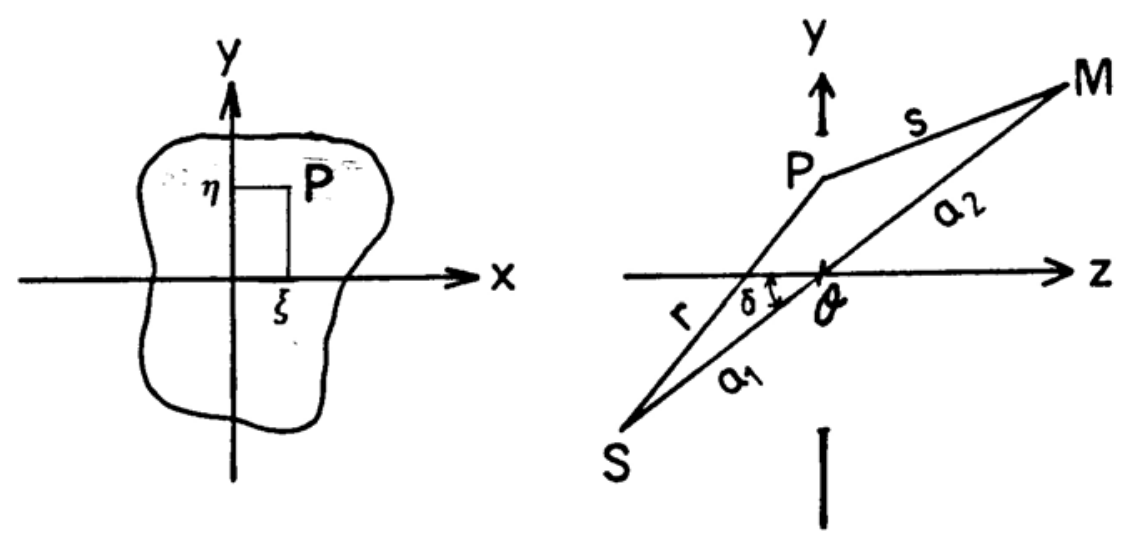

$$
\Phi=j \frac{Q}{8 \pi \lambda} \int_{A} \frac{\mathrm{e}^{-j k(r+s)}}{r s}(\cos (n, r)-\cos (n, s)) \mathrm{d} A
$$

$$
\Phi \cong j \frac{Q}{4 \pi \lambda} \frac{\cos \theta}{a_{1} a_{2}} \int_{A} \mathrm{e}^{-j k(r+s)} \mathrm{d} A
$$

Dimensions of the surface $\ll<a_{1}$ and $a_{2}$ 


\section{Transformation of variables}

Rectangular aperture

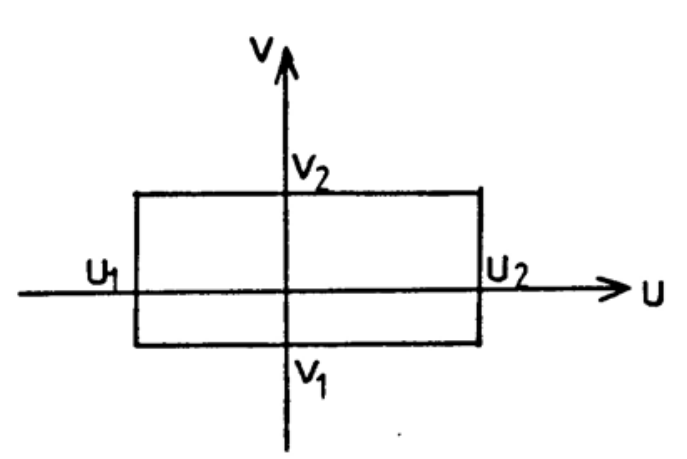

$$
\begin{aligned}
& u=\sqrt{\frac{2}{\lambda}\left(\frac{1}{a_{1}}+\frac{1}{a_{2}}\right)} \cdot \xi \\
& v=\sqrt{\frac{2}{\lambda}\left(\frac{1}{a_{1}}+\frac{1}{a_{2}}\right)} \cdot \cos \theta \cdot \eta
\end{aligned}
$$

$$
\Phi \cong j \frac{Q}{8 \pi} \frac{\mathrm{e}^{-j k\left(a_{1}+a_{2}\right)}}{a_{1}+a_{2}}(M-j N)
$$

$$
M-j N=\int_{u_{1}}^{u_{2}} e^{-j \frac{\pi}{2} u^{2}} \mathrm{~d} u \int_{v_{1}}^{v_{2}} e^{-j \frac{\pi}{2} v^{2}} \mathrm{~d} v
$$

$M-j N=\left[C\left(u_{2}\right)-C\left(u_{1}\right)-j\left(S\left(u_{2}\right)-S\left(u_{1}\right)\right)\right] \cdot\left[C\left(v_{2}\right)-C\left(v_{1}\right)-j\left(S\left(v_{2}\right)-S\left(v_{1}\right)\right)\right]$ 


\section{Cornu's spiral}

The Fresnel integrals:

$$
C(v)=\int_{0}^{v} \cos \left(\frac{\pi}{2} z^{2}\right) \mathrm{d} z \quad S(v)=\int_{0}^{v} \sin \left(\frac{\pi}{2} z^{2}\right) \mathrm{d} z
$$

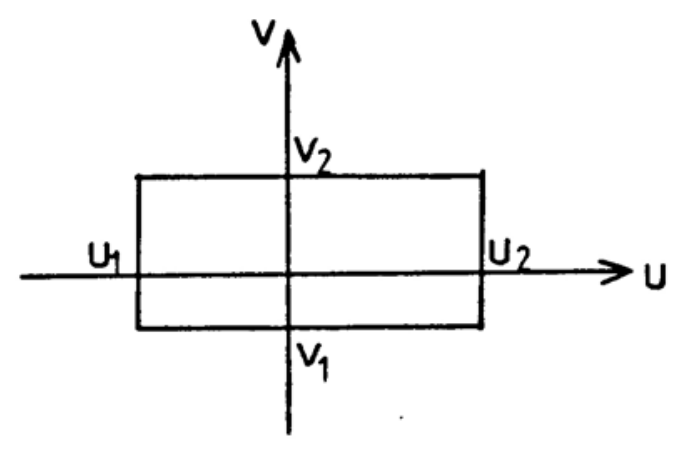

Result for an infinite large surface:

This is taken as the reference for the attenuation due to size

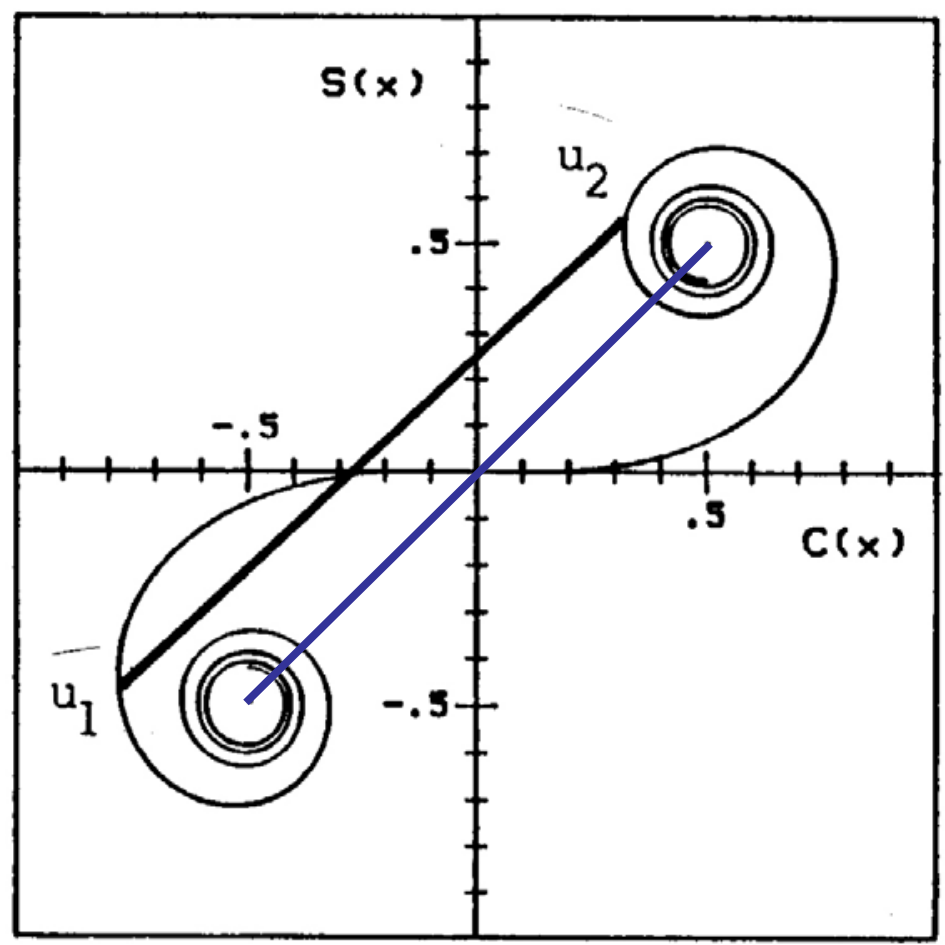




\section{Rectangular reflector}

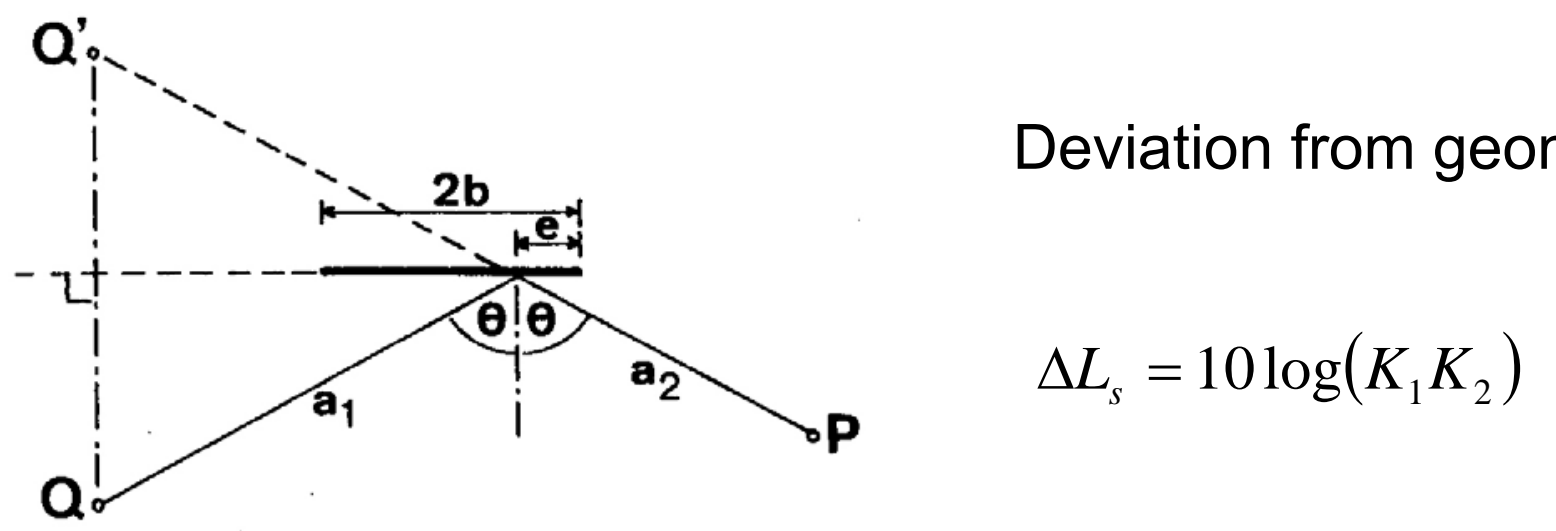

$$
\left.\begin{array}{ll}
K_{1}=\frac{1}{2}\left(\left(C\left(u_{2}\right)-C\left(u_{1}\right)\right)^{2}+\left(S\left(u_{2}\right)-S\left(u_{1}\right)\right)^{2}\right) \\
K_{2}=\frac{1}{2}\left(\left(C\left(v_{2}\right)-C\left(v_{1}\right)\right)^{2}+\left(S\left(v_{2}\right)-S\left(v_{1}\right)\right)^{2}\right)
\end{array}\right\} \quad \text { (Two orthogonal sections) }
$$




\section{Rectangular reflector}
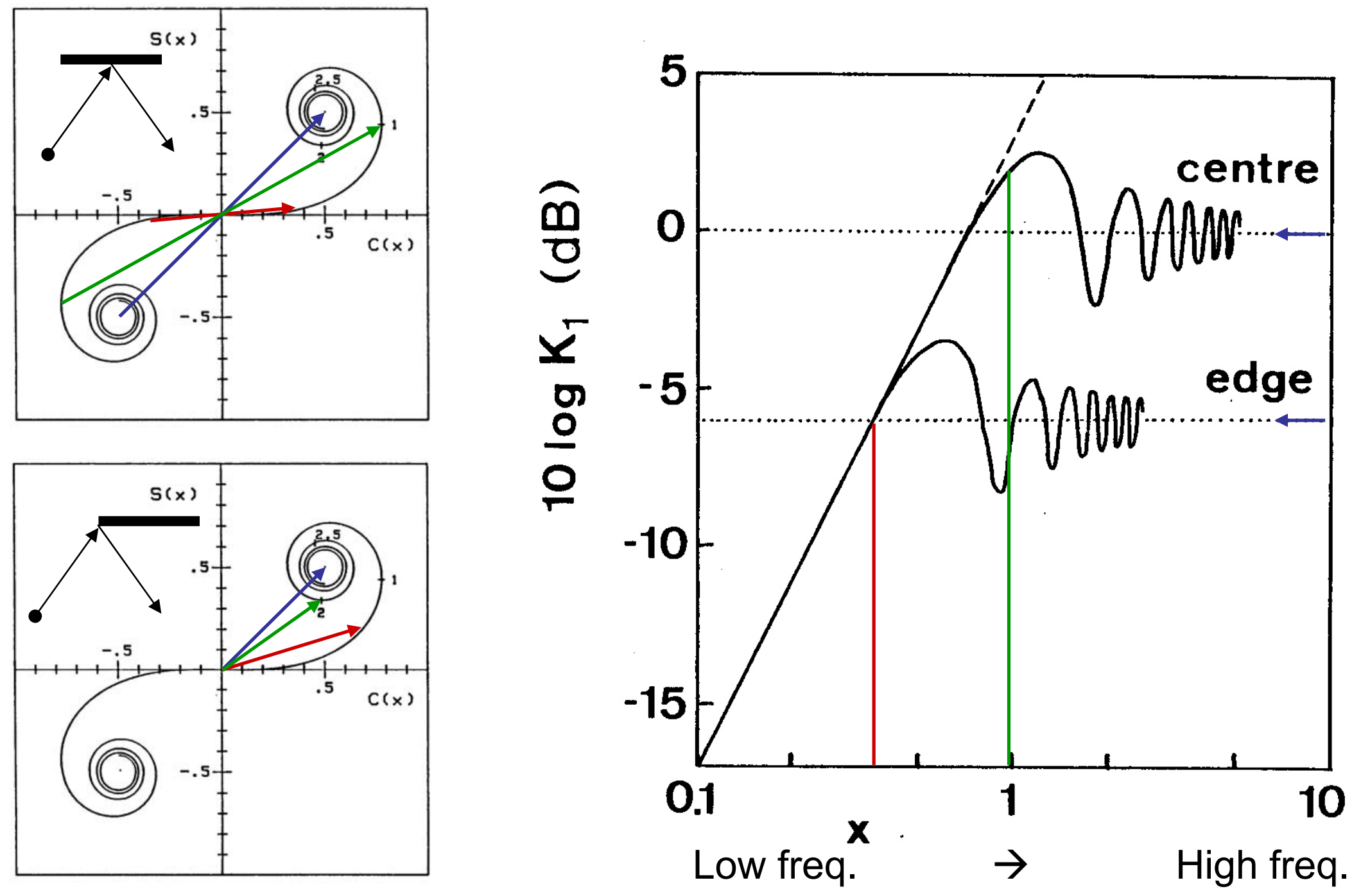


\section{Attenuation due to size - simplified model}

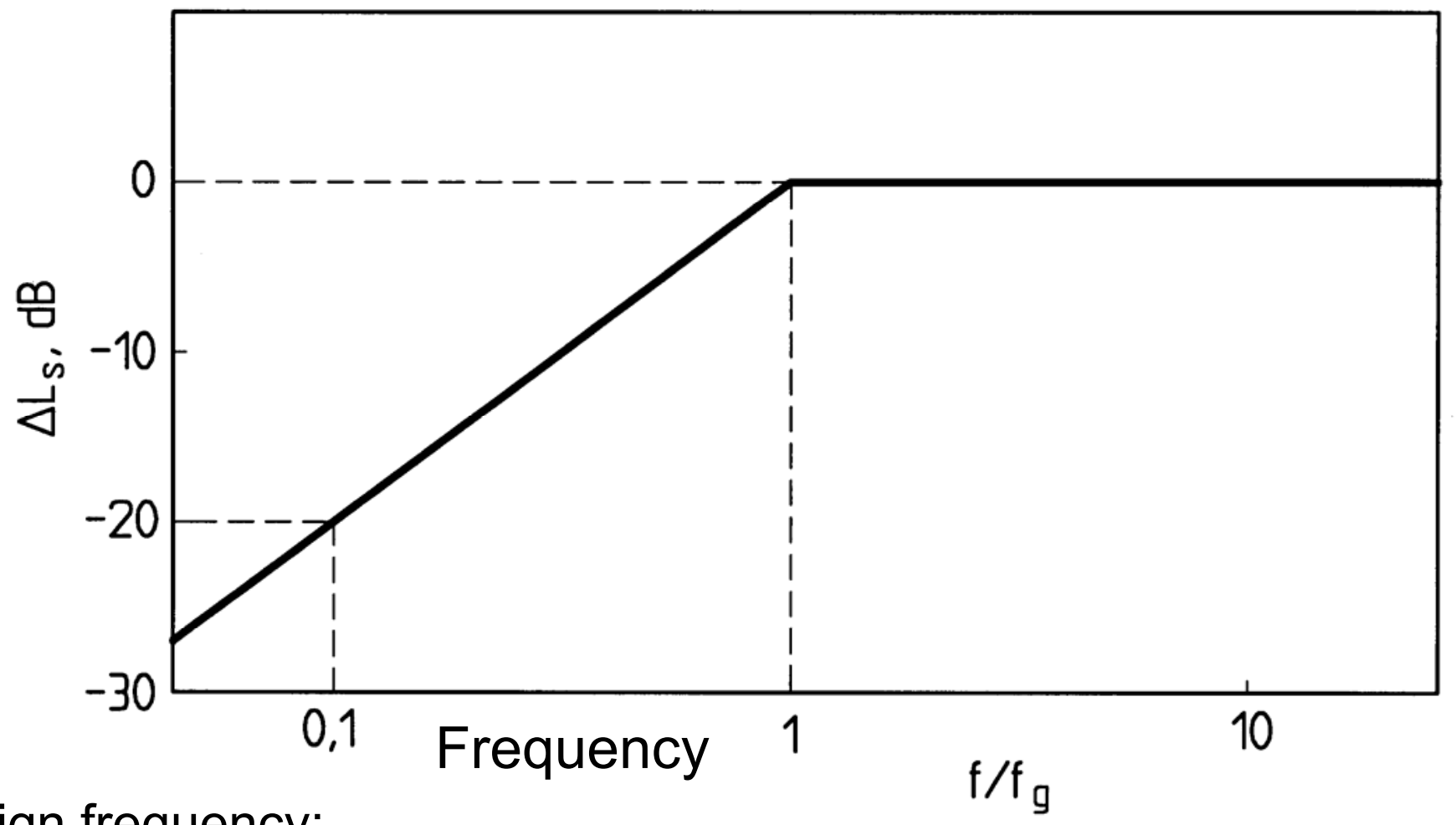

Design frequency:

$$
f_{g}=\frac{c a^{*}}{2 S \cos \theta}
$$

$c=344 \mathrm{~m} / \mathrm{s}$ is speed of sound $\mathrm{a}^{*}$ is characteristic distance $S$ is area of reflector

$\theta$ is angle of incidence 


\section{Measurements using pulse gating technique}

$22 \mathrm{~mm}$ hardboard, $0.6 \mathrm{~m}^{*} 0.6 \mathrm{~m}, \mathrm{a}_{1}=6.0 \mathrm{~m}, \mathrm{a}_{2}=4.0 \mathrm{~m}, \theta=0^{\circ}$

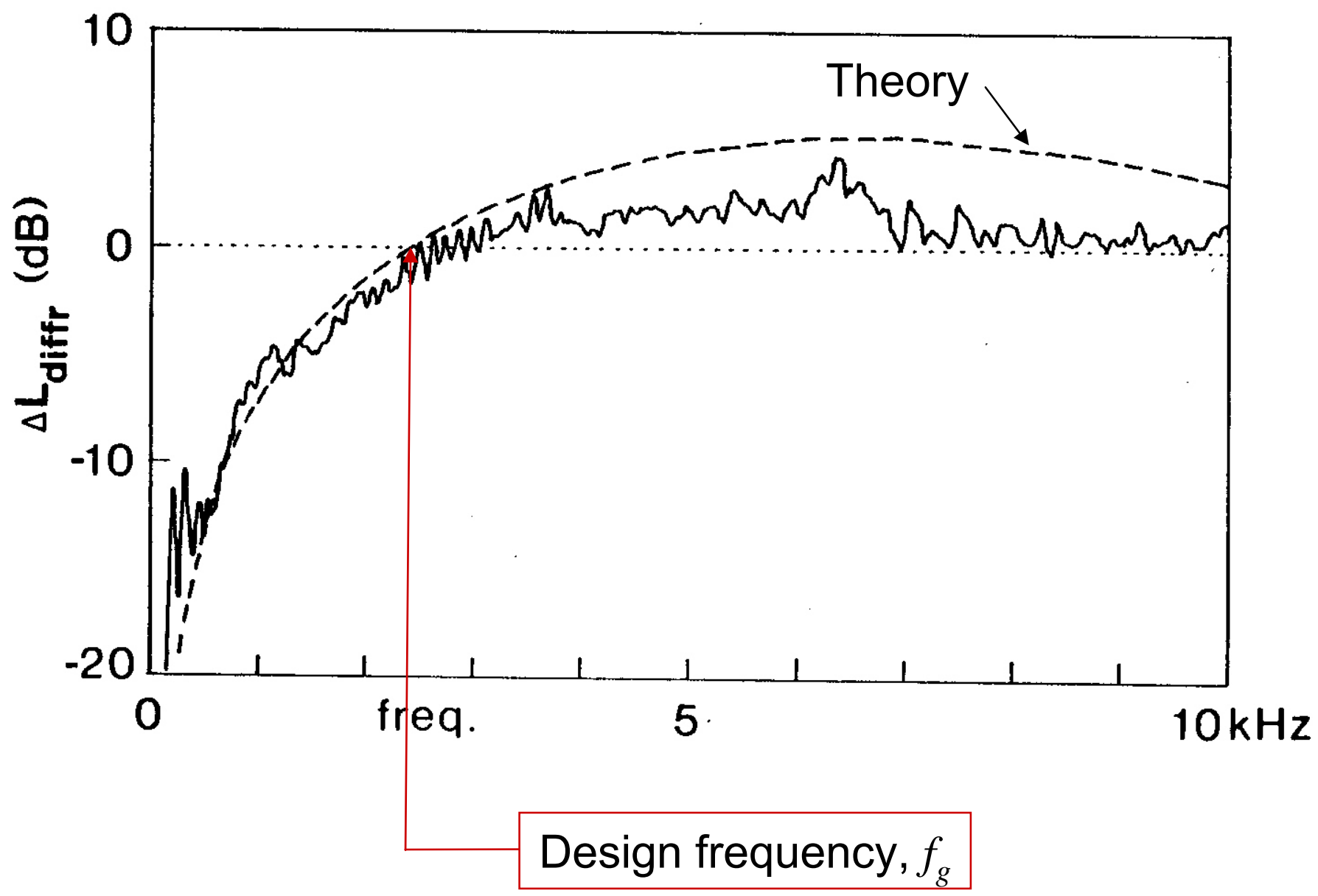




\section{Comment to first results on single reflectors}

- A design frequency was derived from the theory and confirmed by the measurements

- However, this new design frequency is one octave lower than that previously suggested by L. Cremer (1953)

- Cremer agreed that the new design frequency is correct in his last conference paper at ICA 1989 


\section{Measurement results}

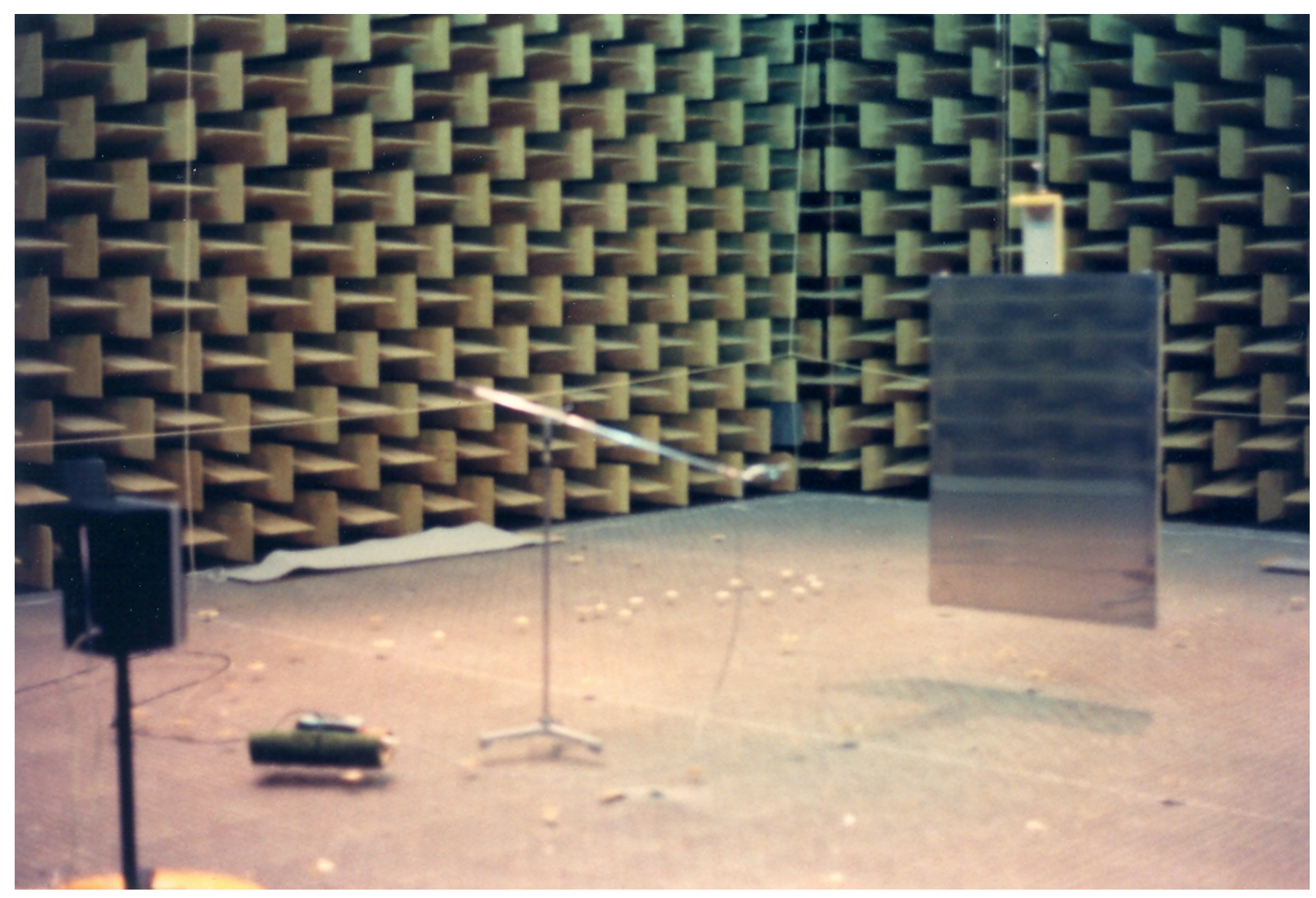


Angle of incidence $=30^{\circ}, a_{1}=3.0 \mathrm{~m}, \mathrm{a}_{2}=3.0 \mathrm{~m}$

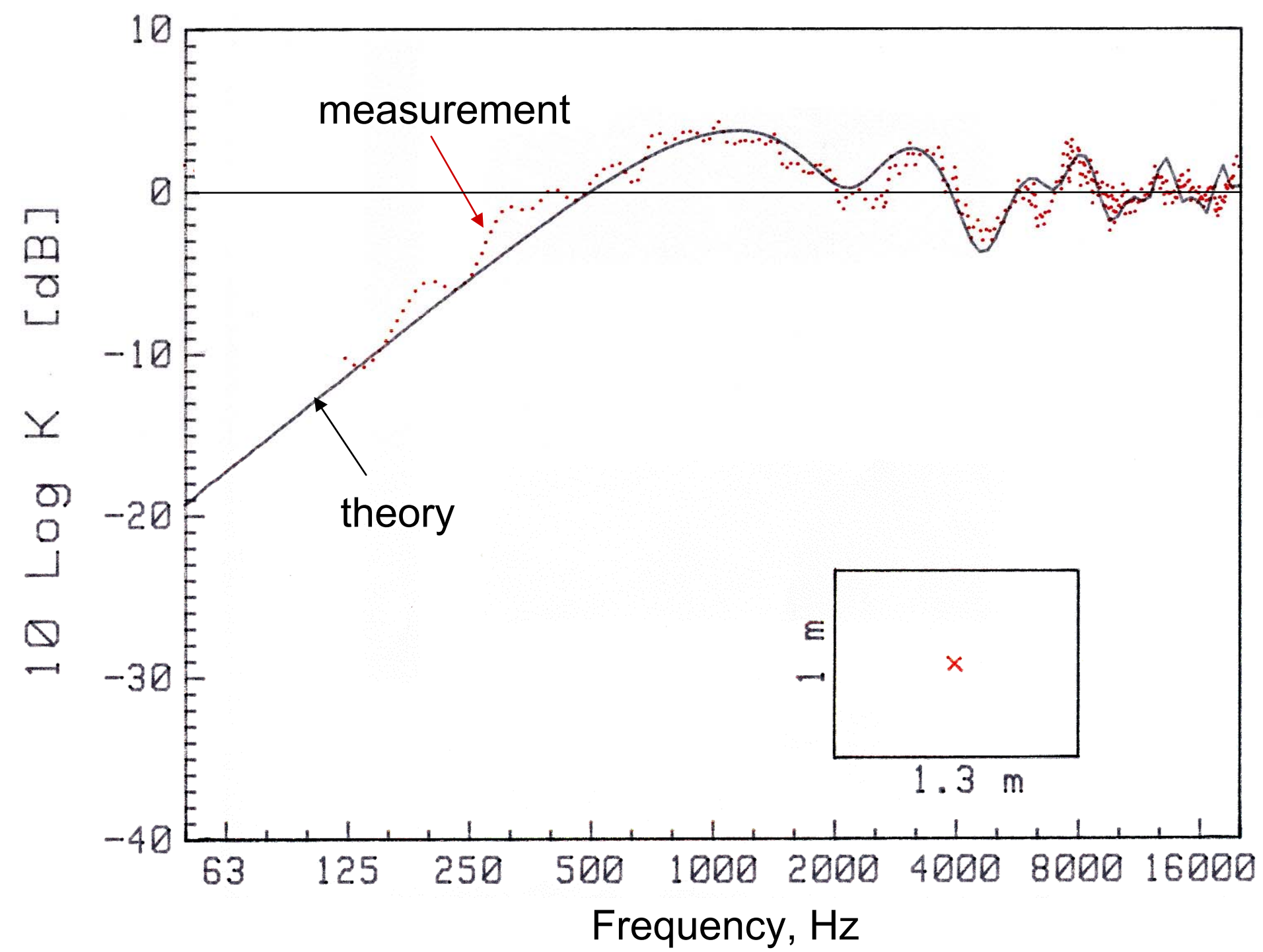


Angle of incidence $=30^{\circ}, a_{1}=3.0 \mathrm{~m}, \mathrm{a}_{2}=3.0 \mathrm{~m}$

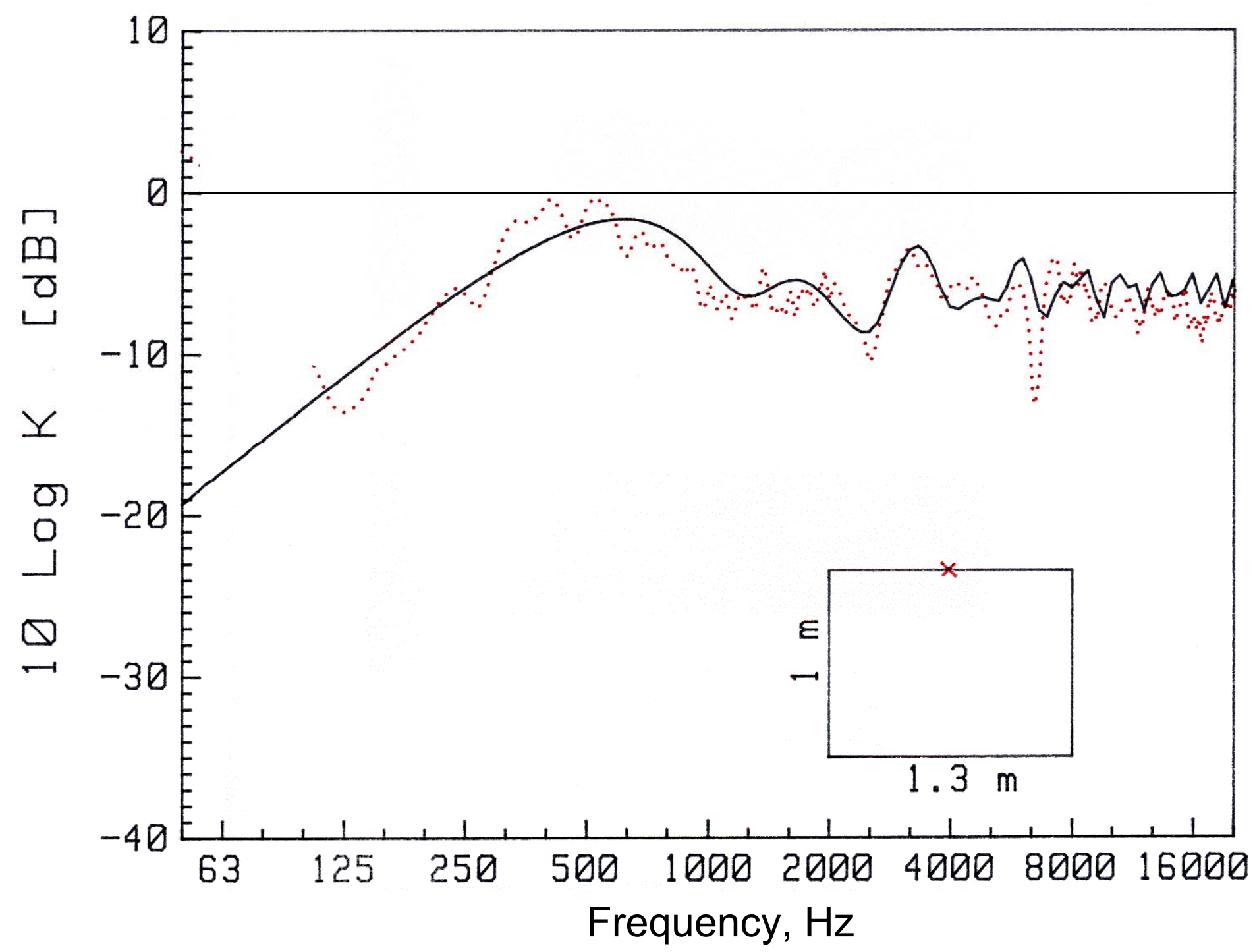


Angle of incidence $=0^{\circ}, a_{1}=4.0 \mathrm{~m}, a_{2}=2.4 \mathrm{~m}$

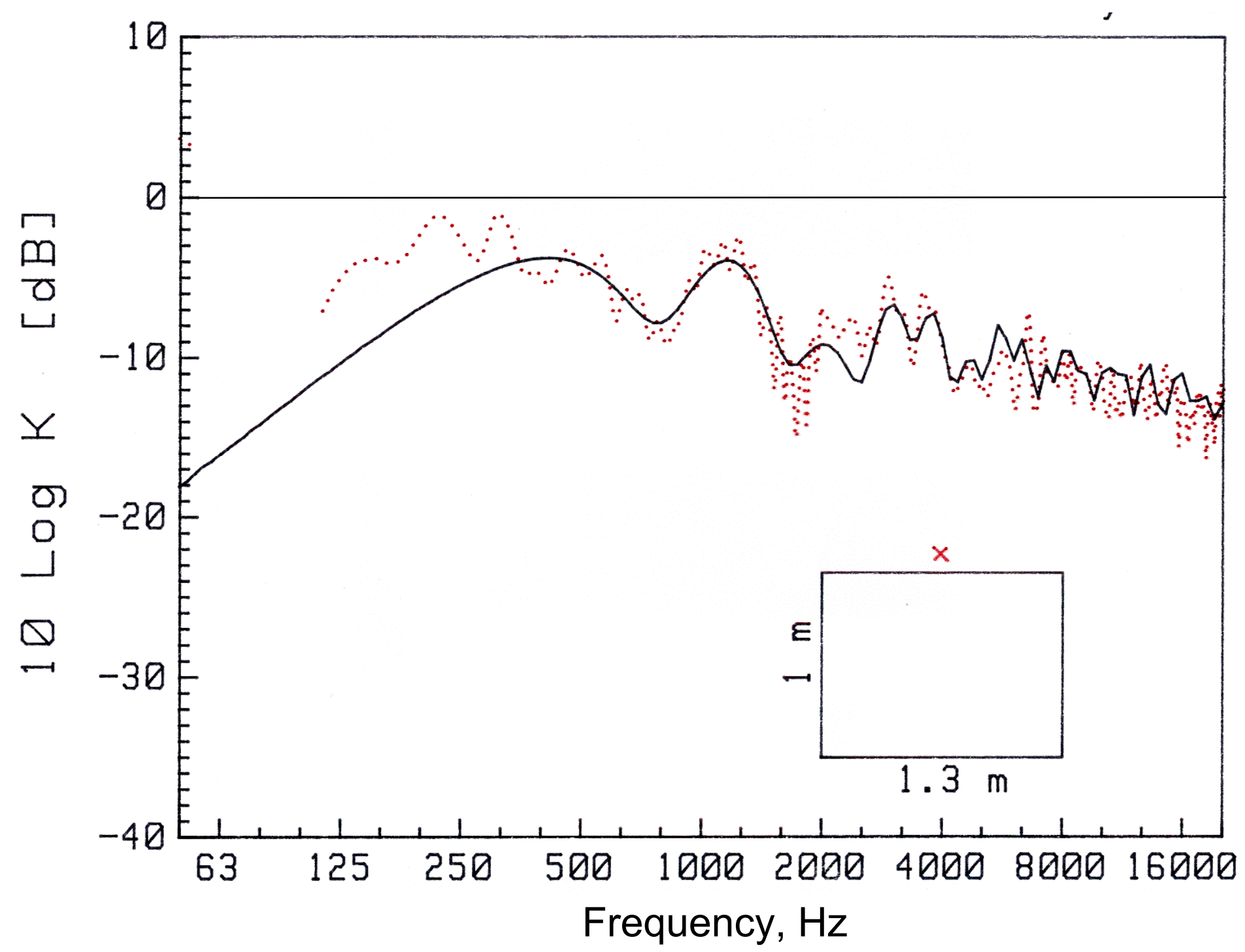




\section{Rotation of reflector}

- to demonstrate that the theoretical model is orthogonal

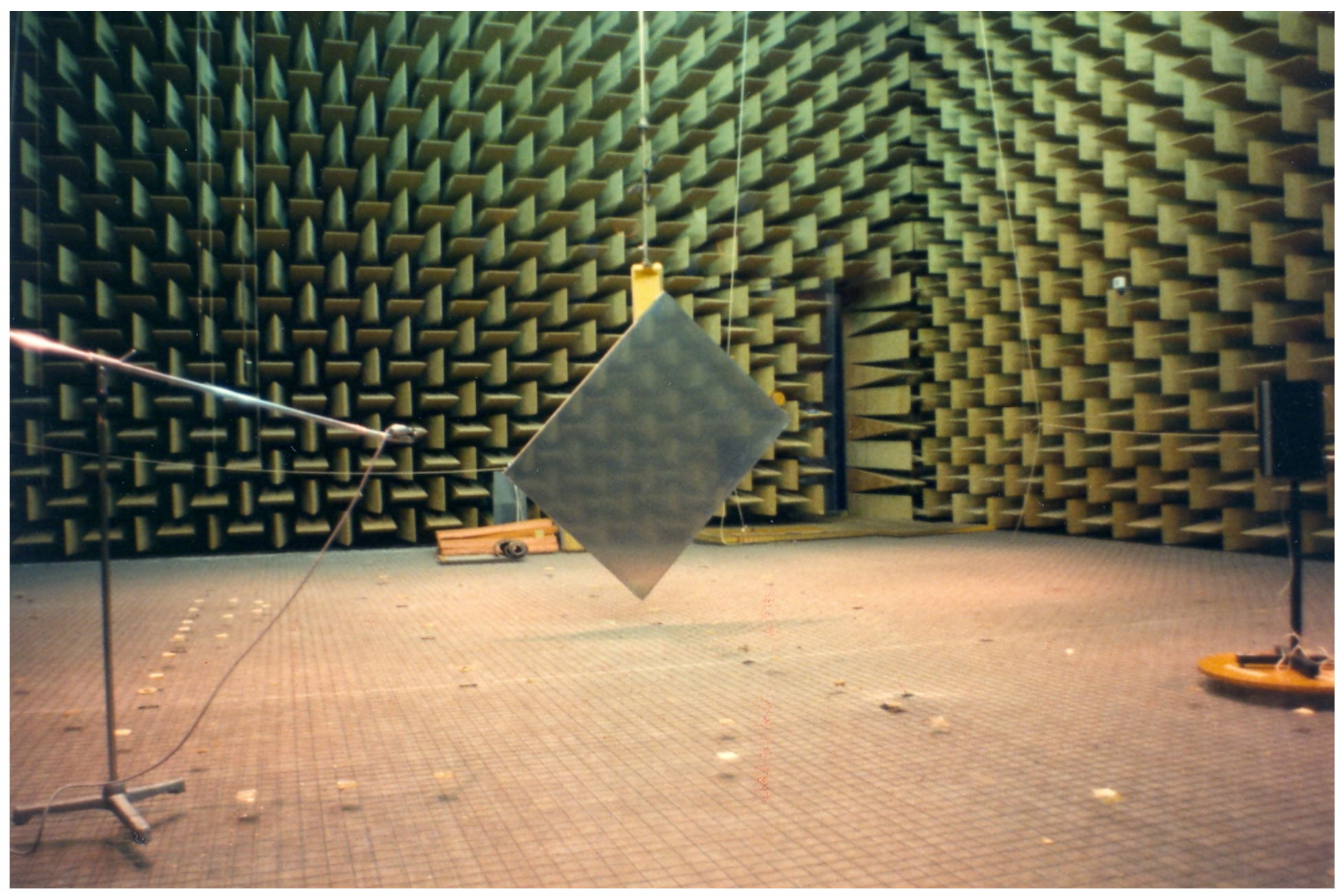


Rotation $30^{\circ} \quad$ Angle of incidence $=30^{\circ}, \mathrm{a}_{1}=3.0 \mathrm{~m}, \mathrm{a}_{2}=3.0 \mathrm{~m}$

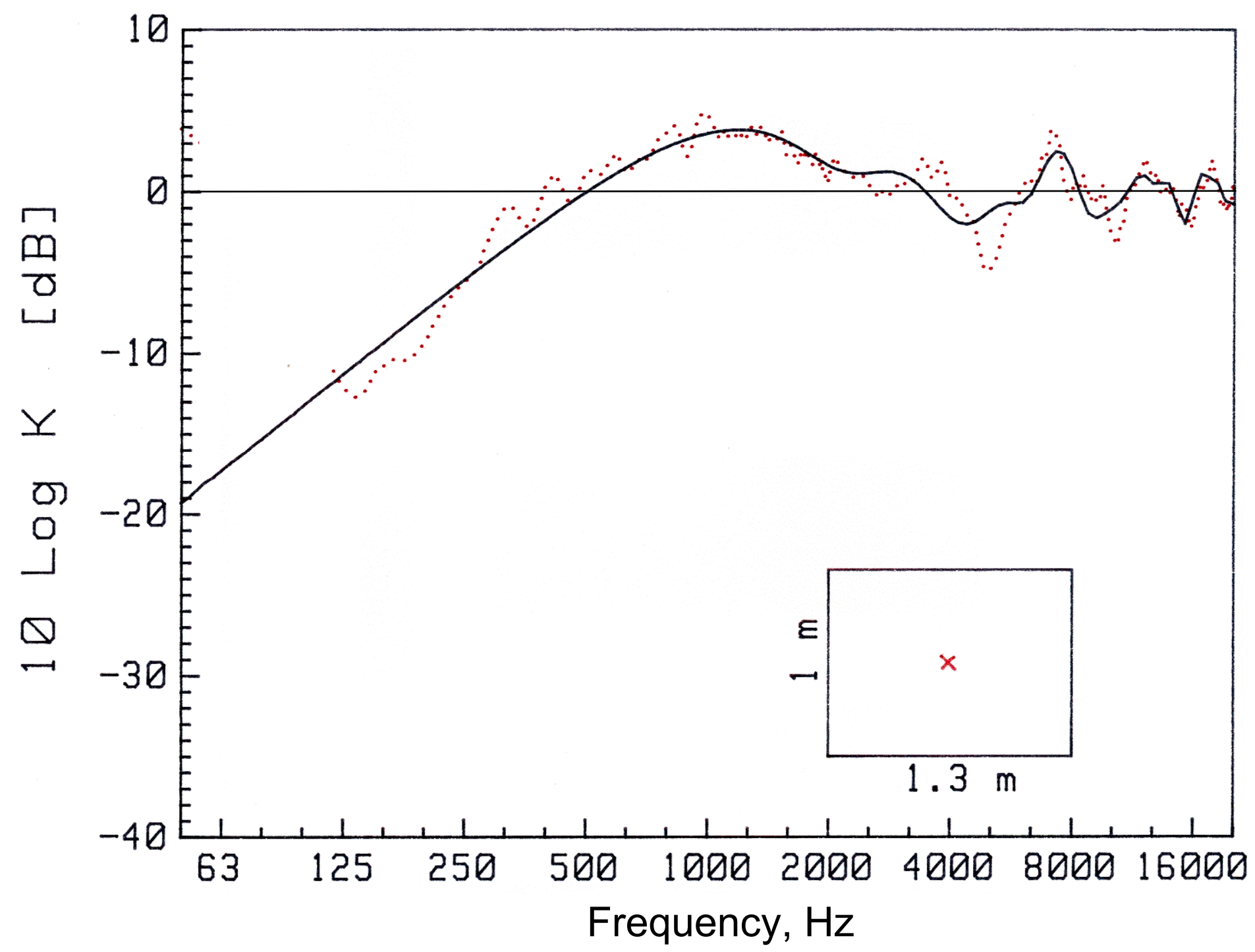




\section{Reflector array}

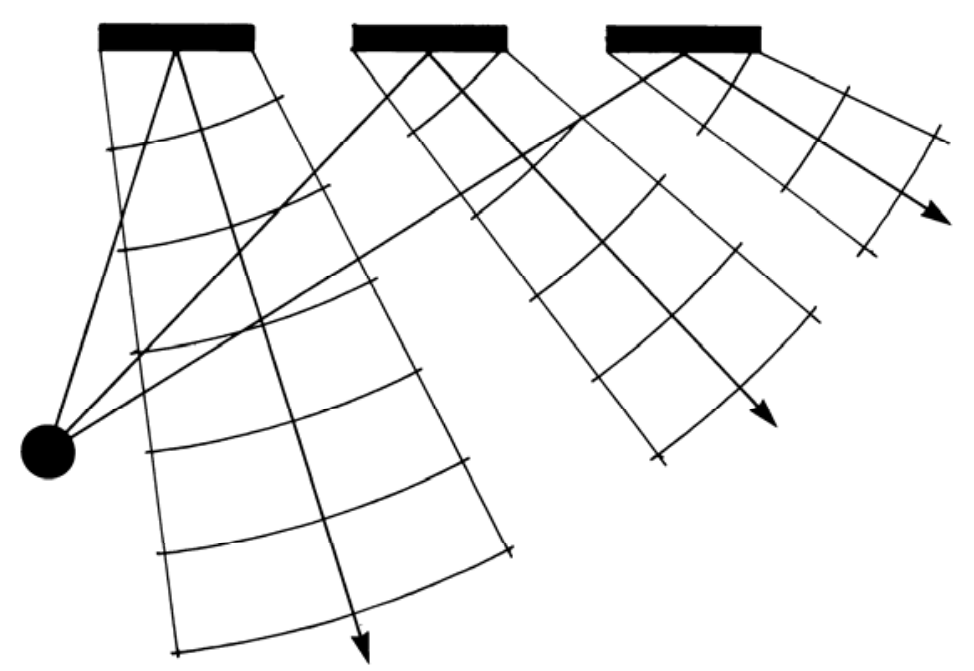

References:

1988: Bølgeteoretiske metoder. (In Danish). Romakustisk prosjektering, NIF kursus, Geilo. (17 p).

1990: The Design of an Array of Reflectors for Improved Ensemble on a Concert Hall Platform. NAM-90, Luleå. Proceedings pp. 129-134.

1990: Attenuation of Sound Reflections from an Array of Reflectors. 29th Conference on Acoustics, Strbské Pleso. Proceedings pp. 231-234.

1991: Design of New Ceiling Reflectors for Improved Ensemble in a Concert Hall.

Applied Acoustics 34, pp. 7-17. 


\section{Reflector array}

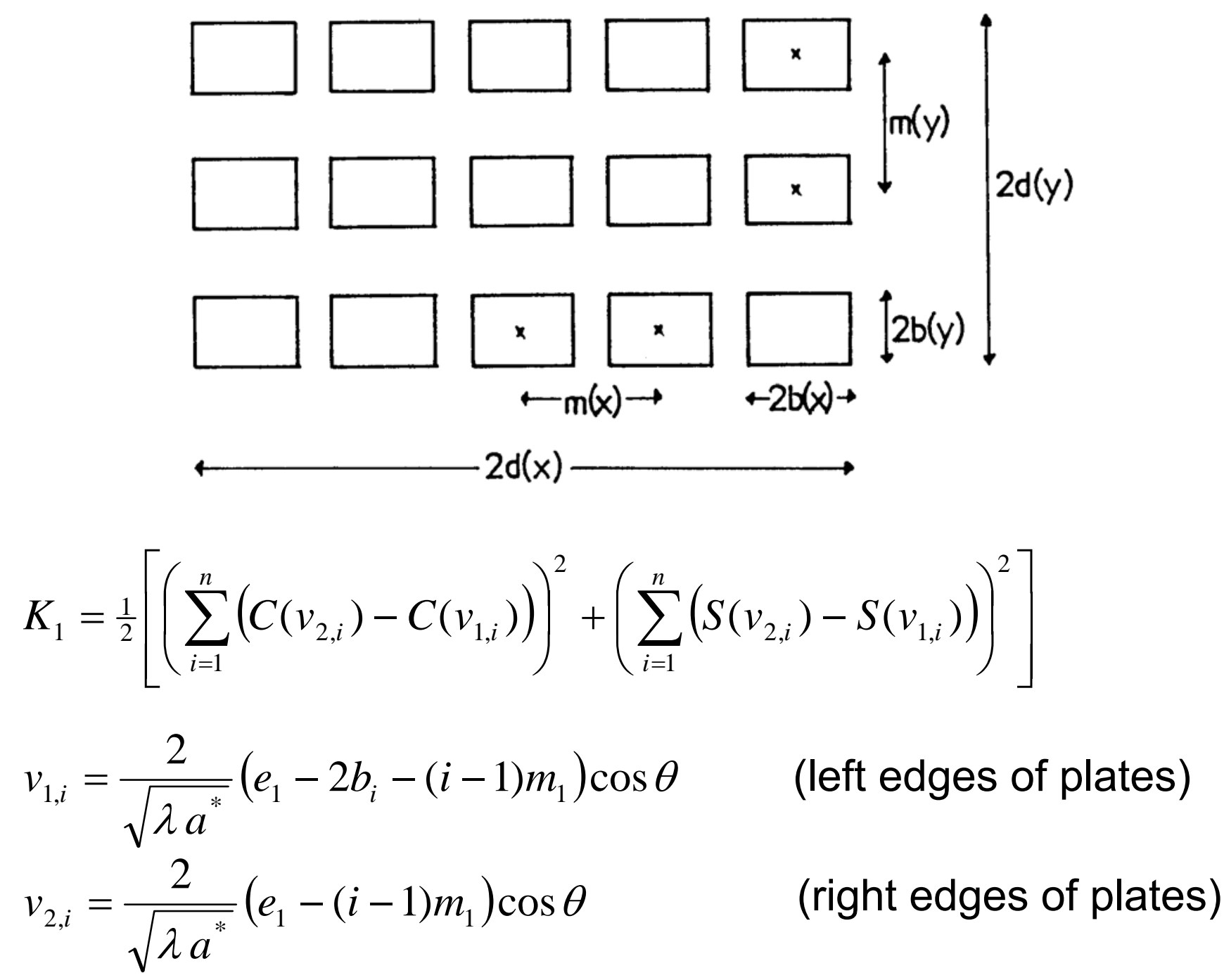



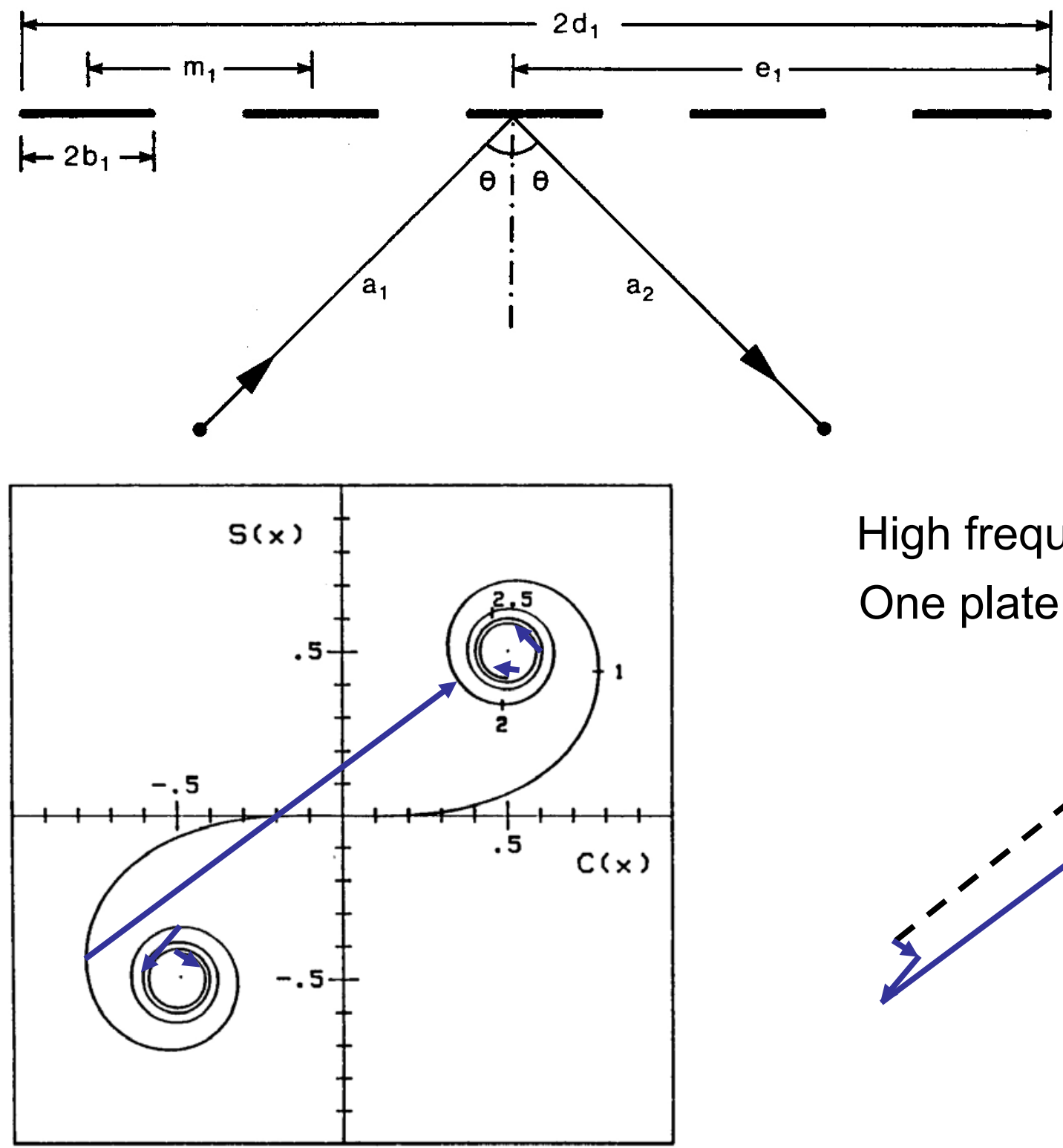

High frequencies:

One plate dominates

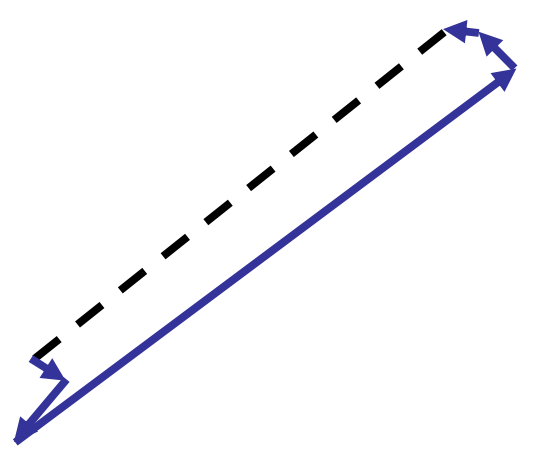



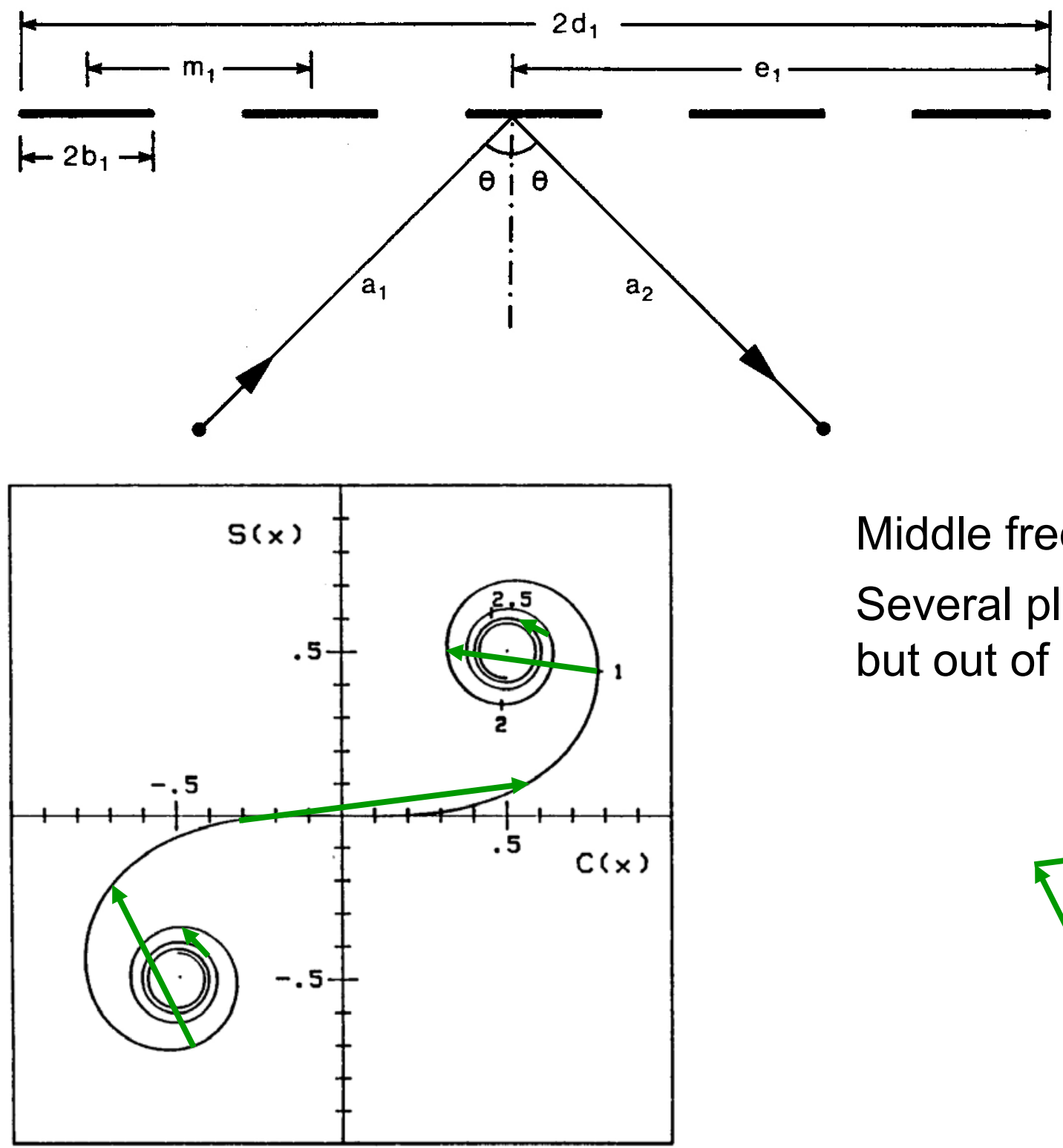

Middle frequencies:

Several plates contribute, but out of phase

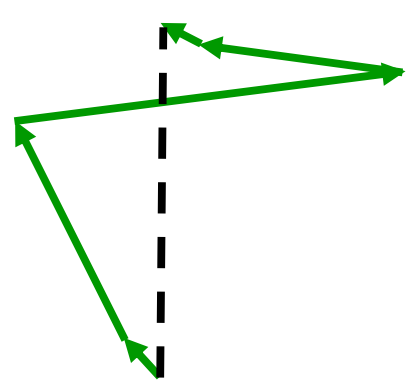



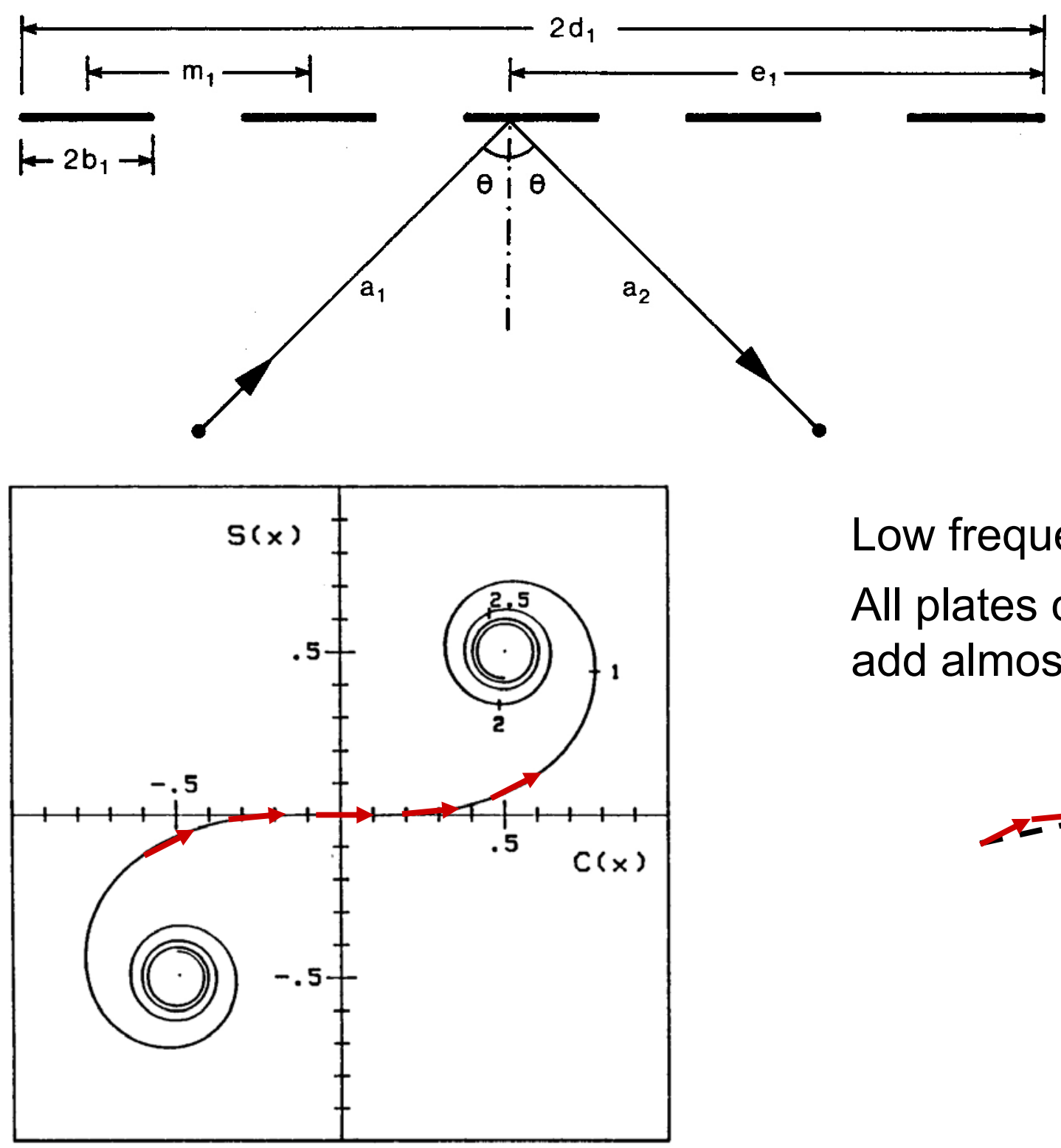

Low frequencies:

All plates contribute, and add almost in phase

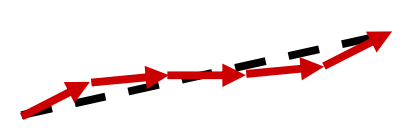




\section{Measurement results}

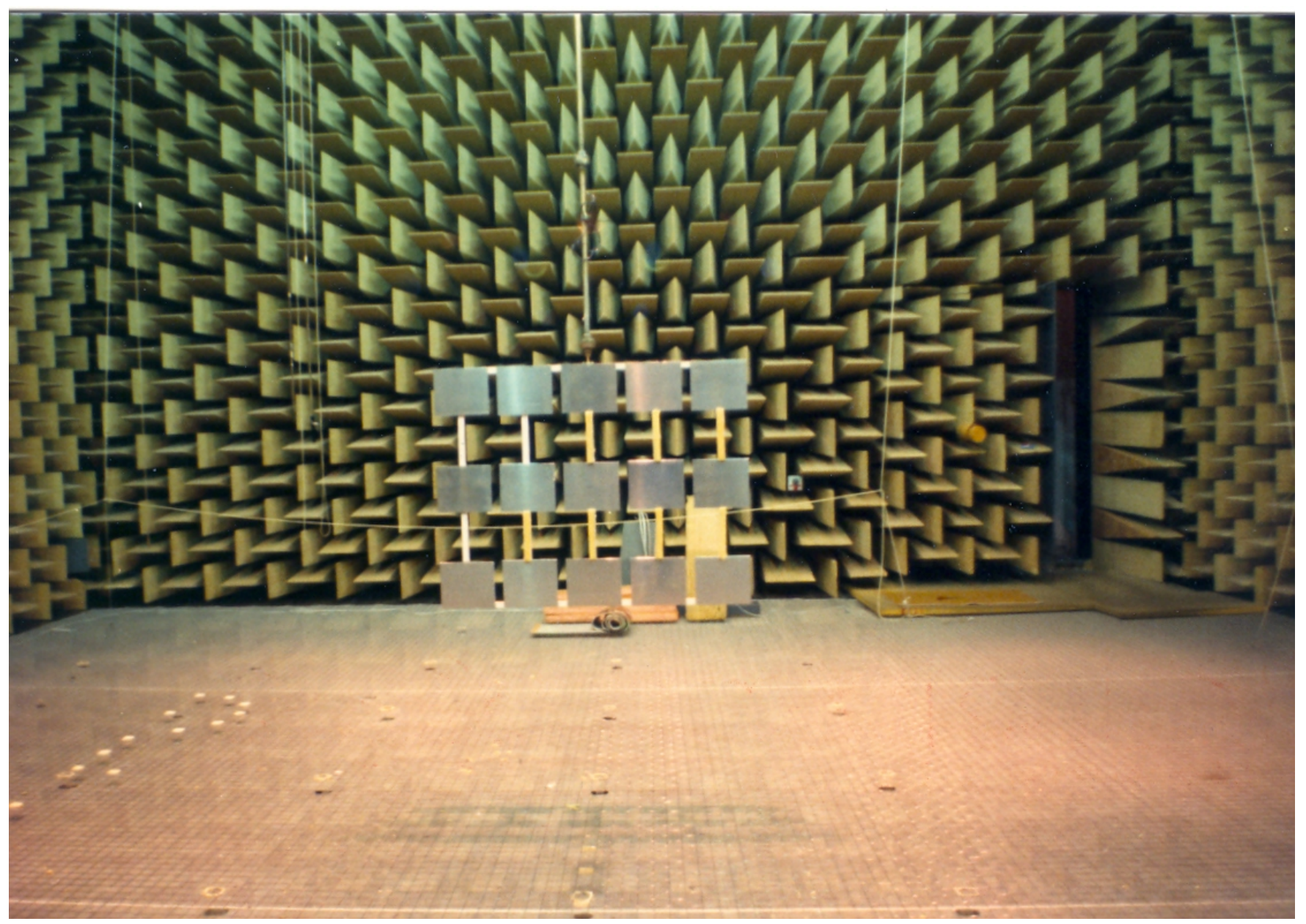


Plate dimensions: $0.23 \mathrm{~m}^{*} 0.20 \mathrm{~m}, \theta=30^{\circ}, \mathrm{a}_{1}=3.0 \mathrm{~m}, \mathrm{a}_{2}=2.0 \mathrm{~m}$

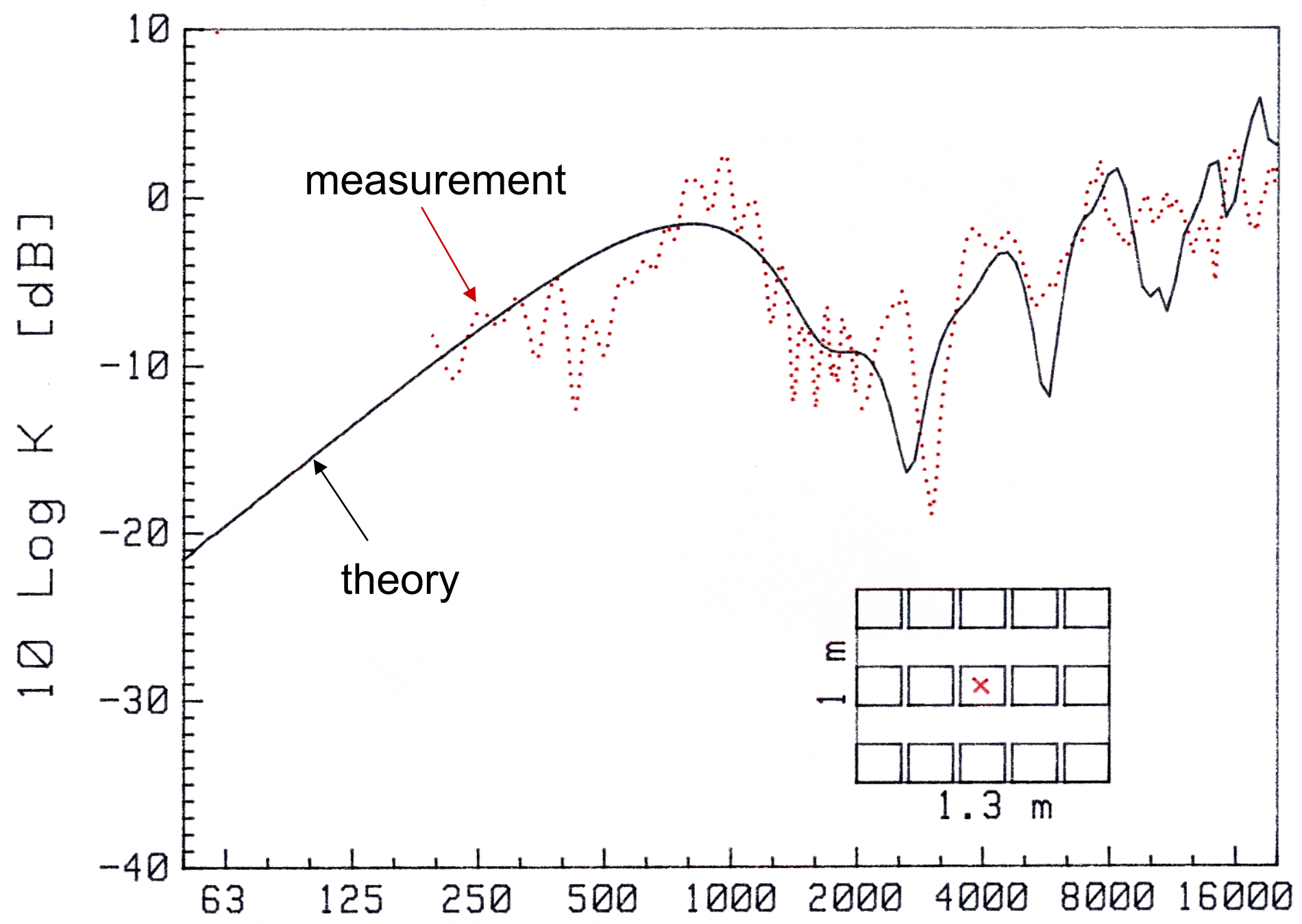


Plate dimensions: $0.23 \mathrm{~m}^{*} 0.20 \mathrm{~m}, \theta=30^{\circ}, \mathrm{a}_{1}=3.0 \mathrm{~m}, \mathrm{a}_{2}=2.0 \mathrm{~m}$

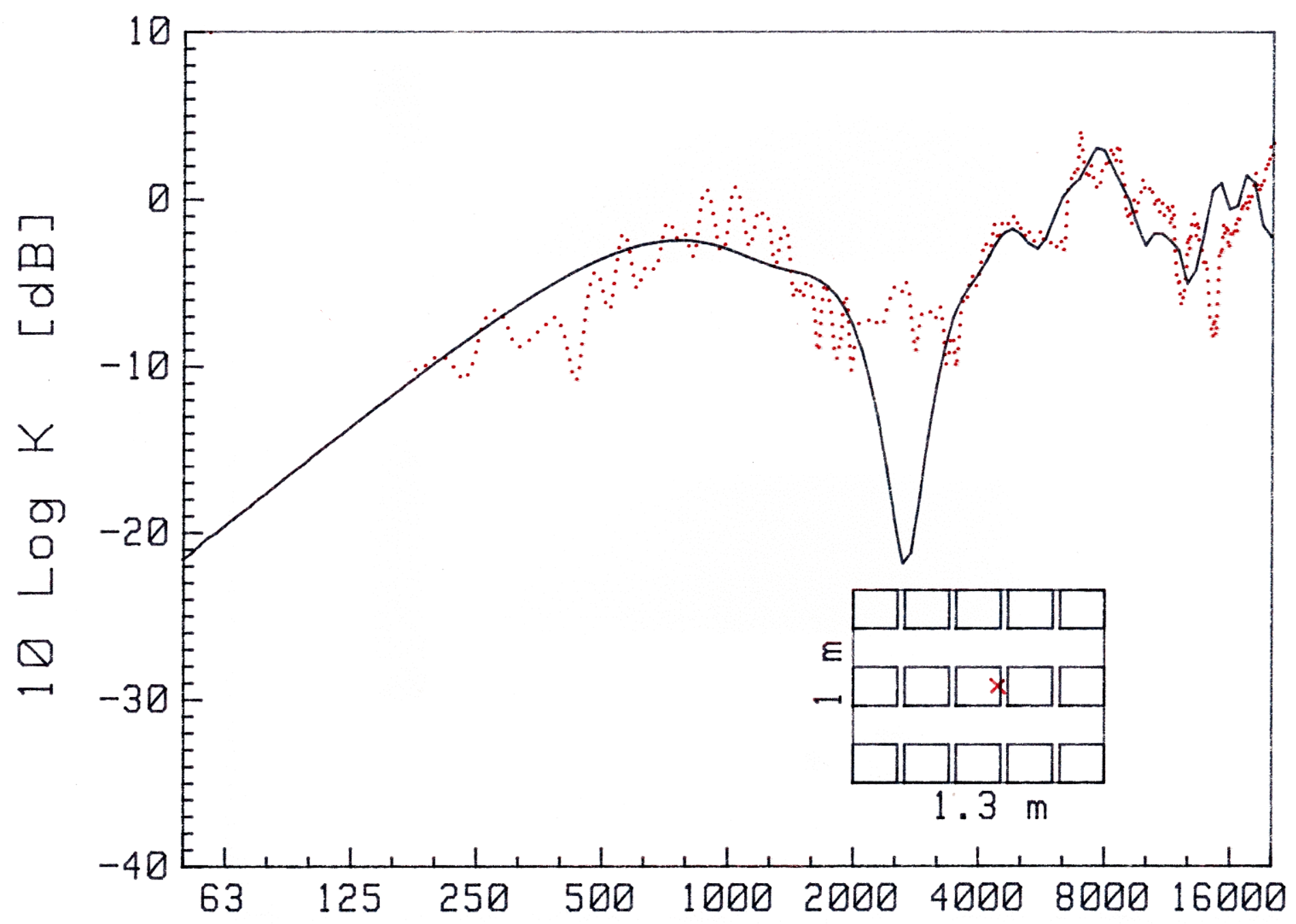


Plate dimensions: $0.23 \mathrm{~m}^{*} 0.20 \mathrm{~m}, \theta=30^{\circ}, \mathrm{a}_{1}=3.0 \mathrm{~m}, \mathrm{a}_{2}=2.0 \mathrm{~m}$

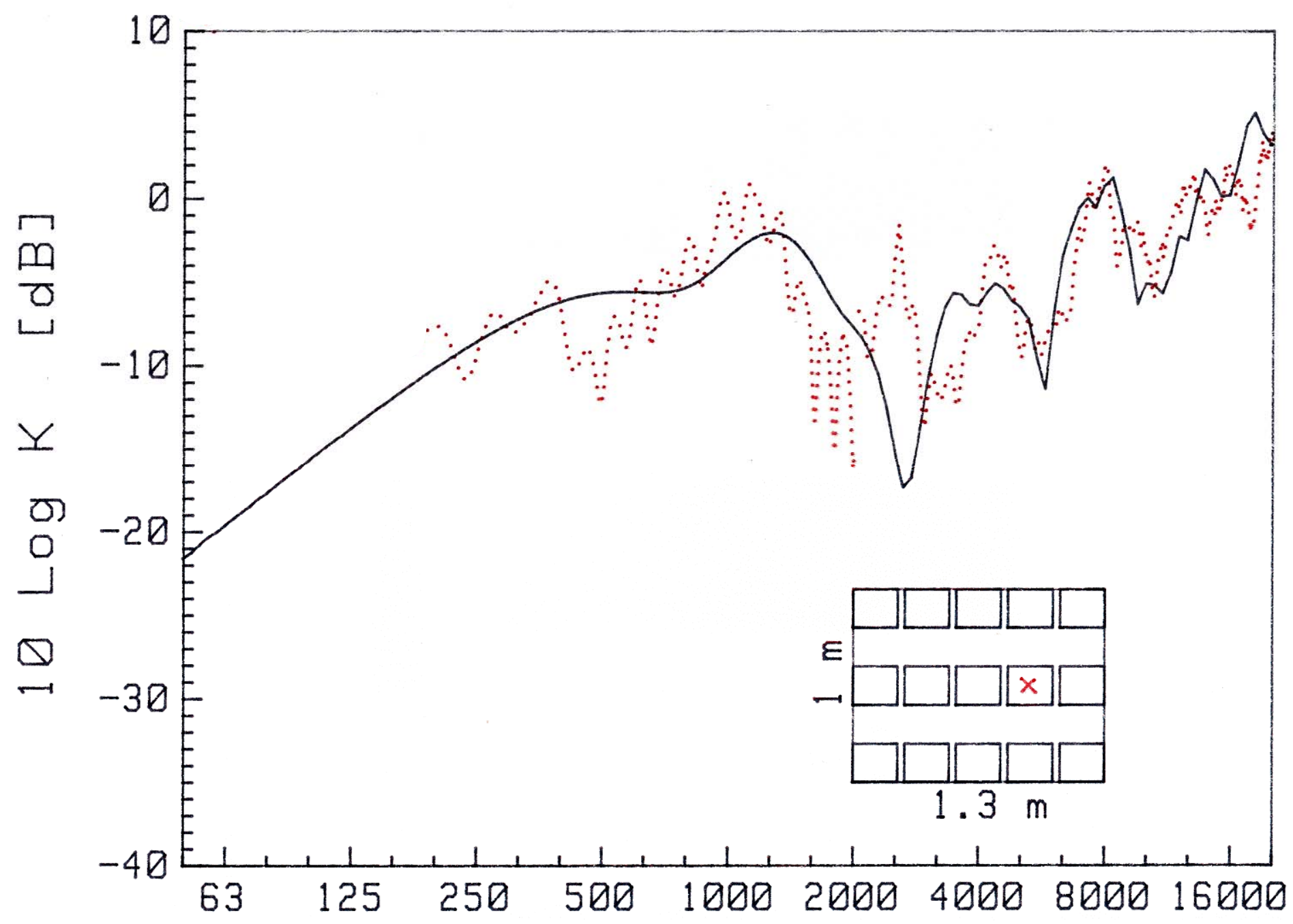


Plate dimensions: $0.23 \mathrm{~m}^{*} 0.20 \mathrm{~m}, \theta=30^{\circ}, \mathrm{a}_{1}=3.0 \mathrm{~m}, \mathrm{a}_{2}=2.0 \mathrm{~m}$

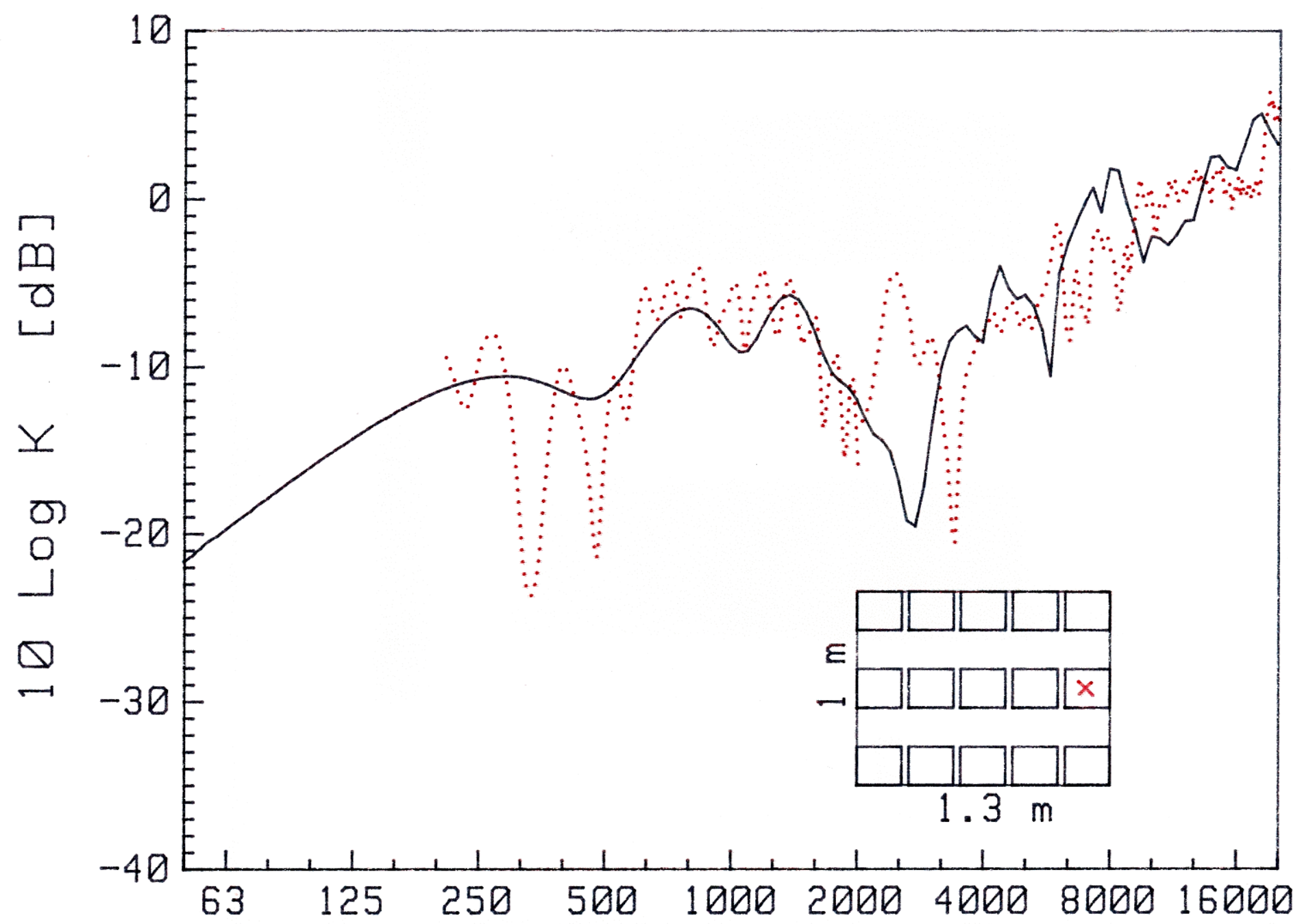


Plate dimensions: $0.23 \mathrm{~m}^{*} 0.20 \mathrm{~m}, \theta=30^{\circ}, \mathrm{a}_{1}=3.0 \mathrm{~m}, \mathrm{a}_{2}=2.0 \mathrm{~m}$

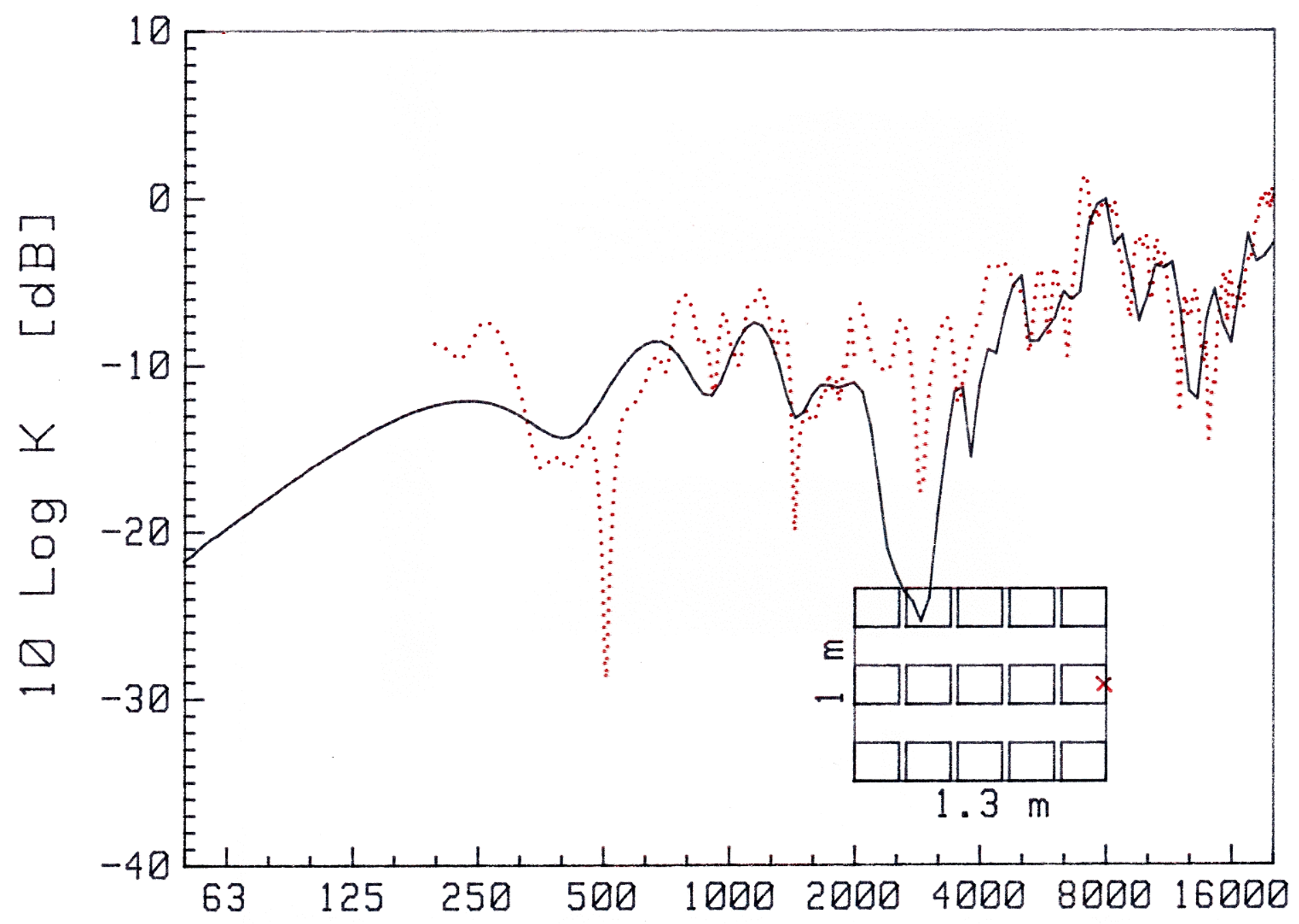




\section{Reflector array - Parameter study}

Best position

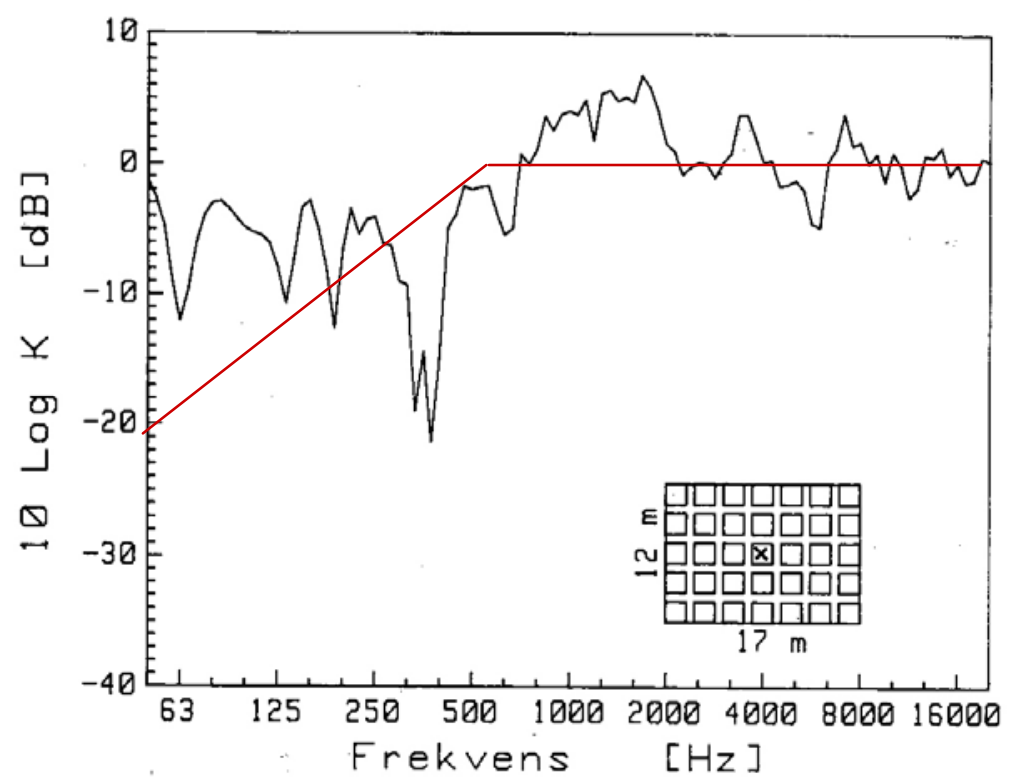

Worst position (near centre)

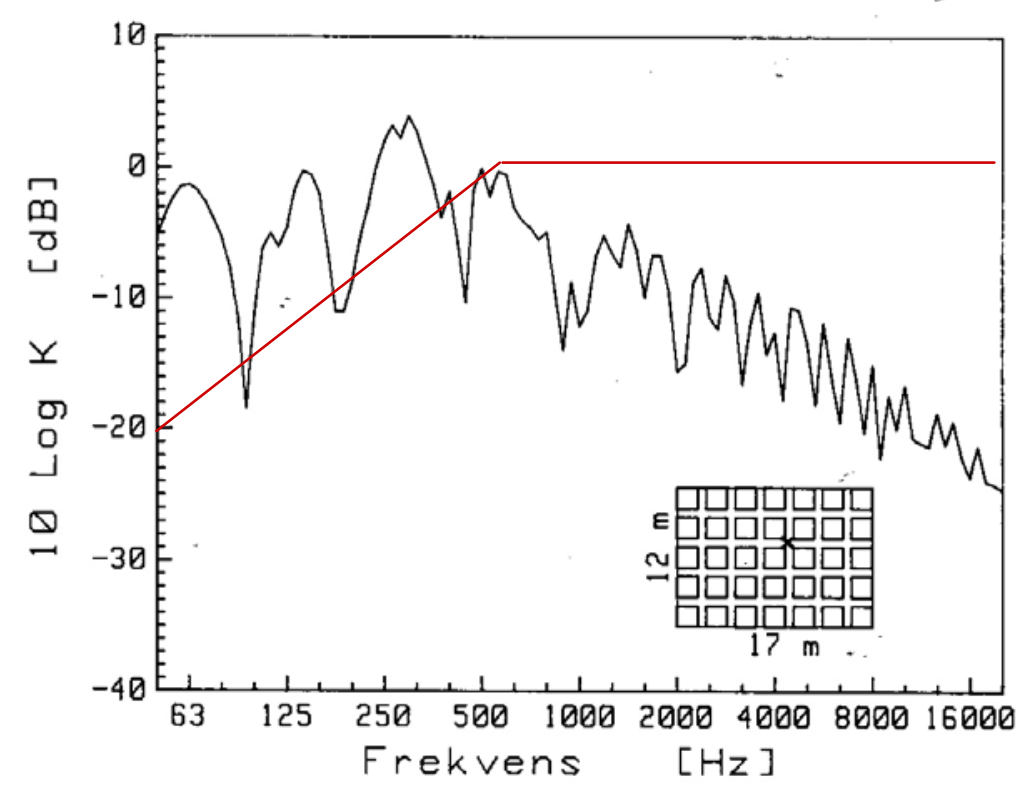

Panel size: $1.8 \mathrm{~m} * 1.8 \mathrm{~m}$, angle of incidence $=45^{\circ}, a_{1}=a_{2}=7.1 \mathrm{~m}$ Density of array: $\mu=50 \%$ 


\section{Reflector array - Parameter study}

Best position

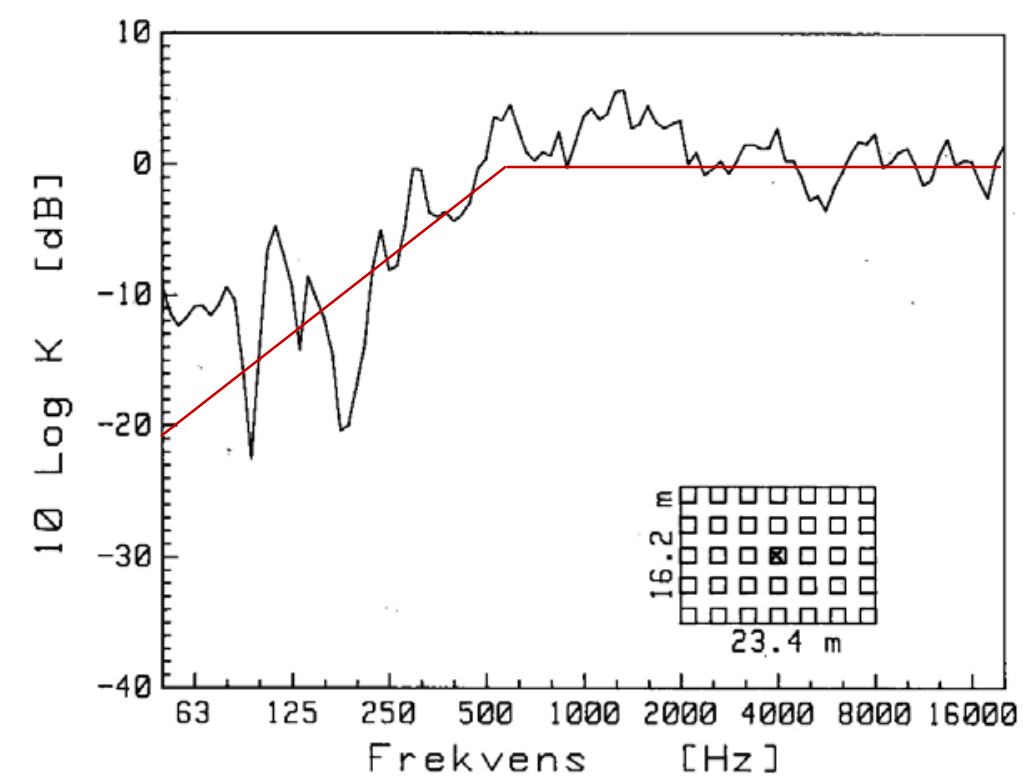

Worst position (near centre)

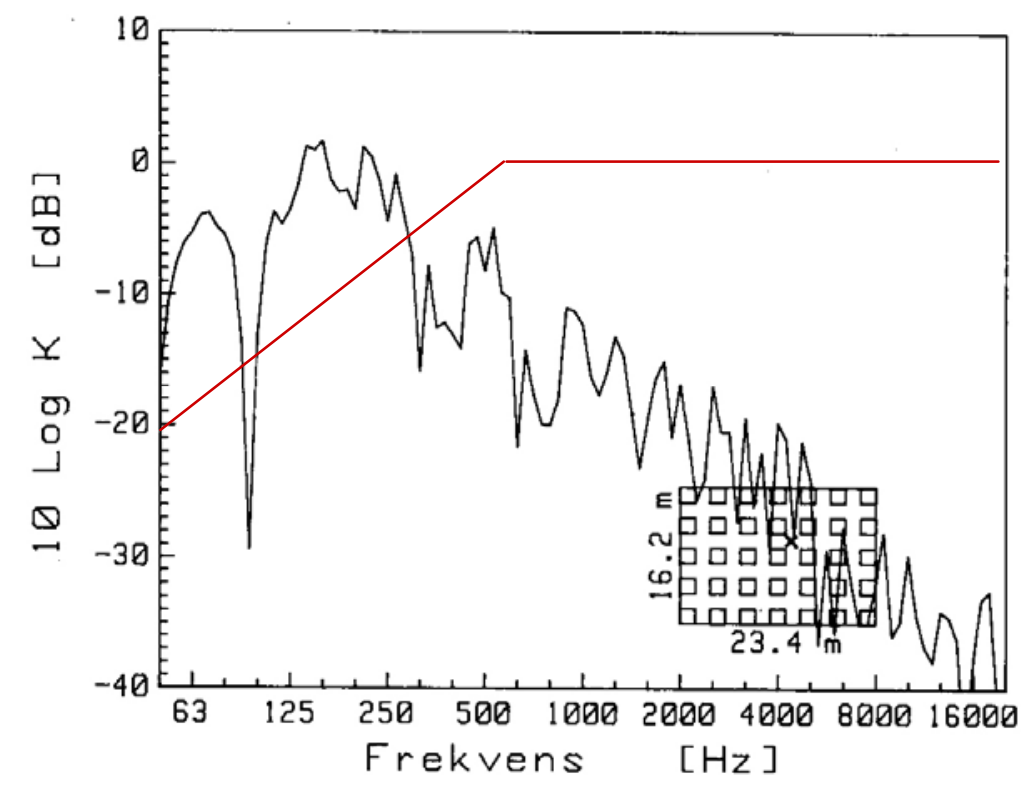

Panel size: $1.8 \mathrm{~m} * 1.8 \mathrm{~m}$, angle of incidence $=45^{\circ}, \mathrm{a}_{1}=\mathrm{a}_{2}=7.1 \mathrm{~m}$ Density of array: $\mu=25 \%$ 


\section{Reflector array - Parameter study}

Best position



Worst position (near centre)

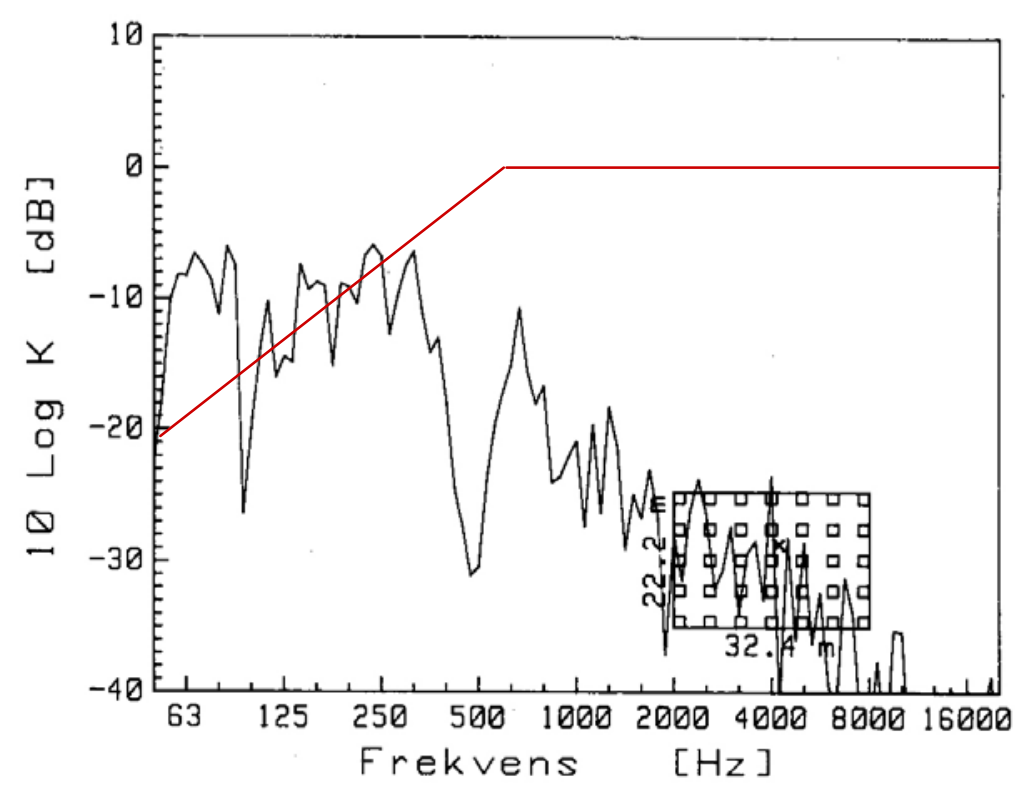

Panel size: $1.8 \mathrm{~m} * 1.8 \mathrm{~m}$, angle of incidence $=45^{\circ}, \mathrm{a}_{1}=\mathrm{a}_{2}=7.1 \mathrm{~m}$ Density of array: $\mu=12.5 \%$ 


\section{Reflector array - Parameter study}

Best position

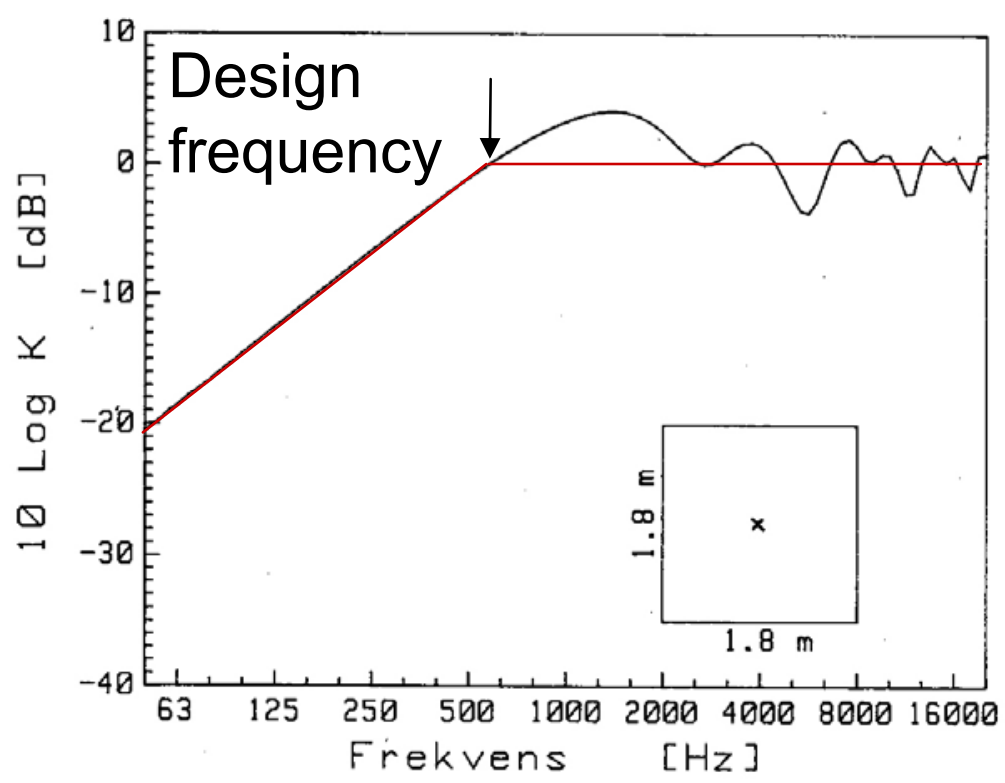

Worst position (near centre)

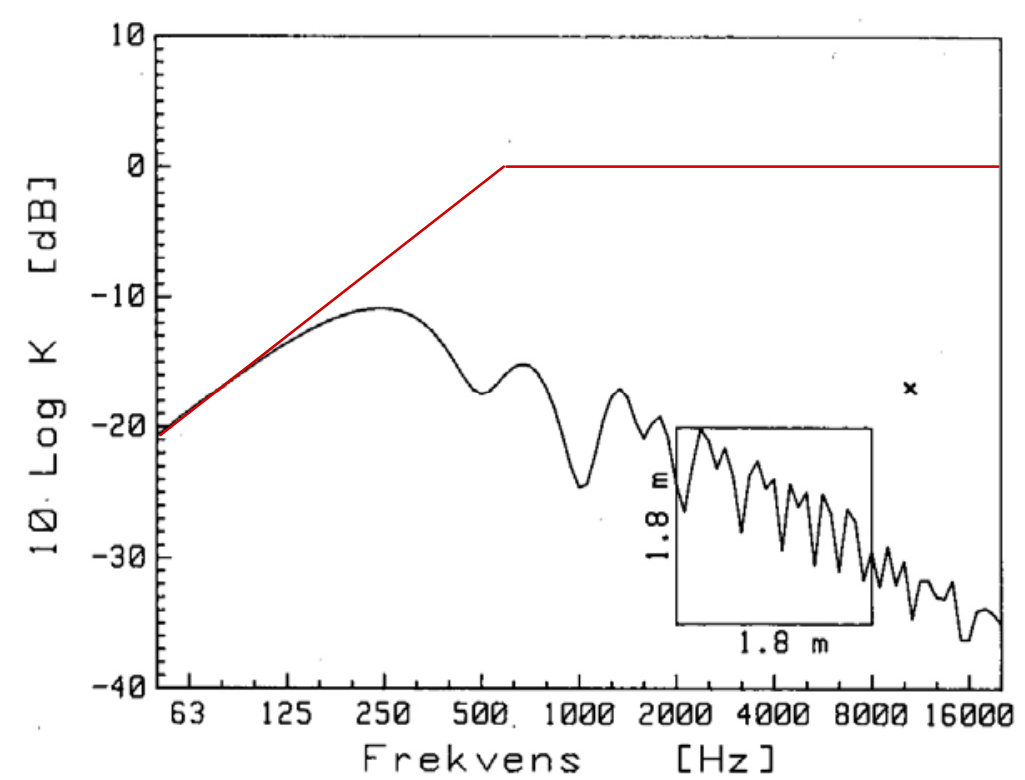

Panel size: $1.8 \mathrm{~m} * 1.8 \mathrm{~m}$, angle of incidence $=45^{\circ}, a_{1}=a_{2}=7.1 \mathrm{~m}$ One single plate, only 


\section{Reflector array - A design guide}

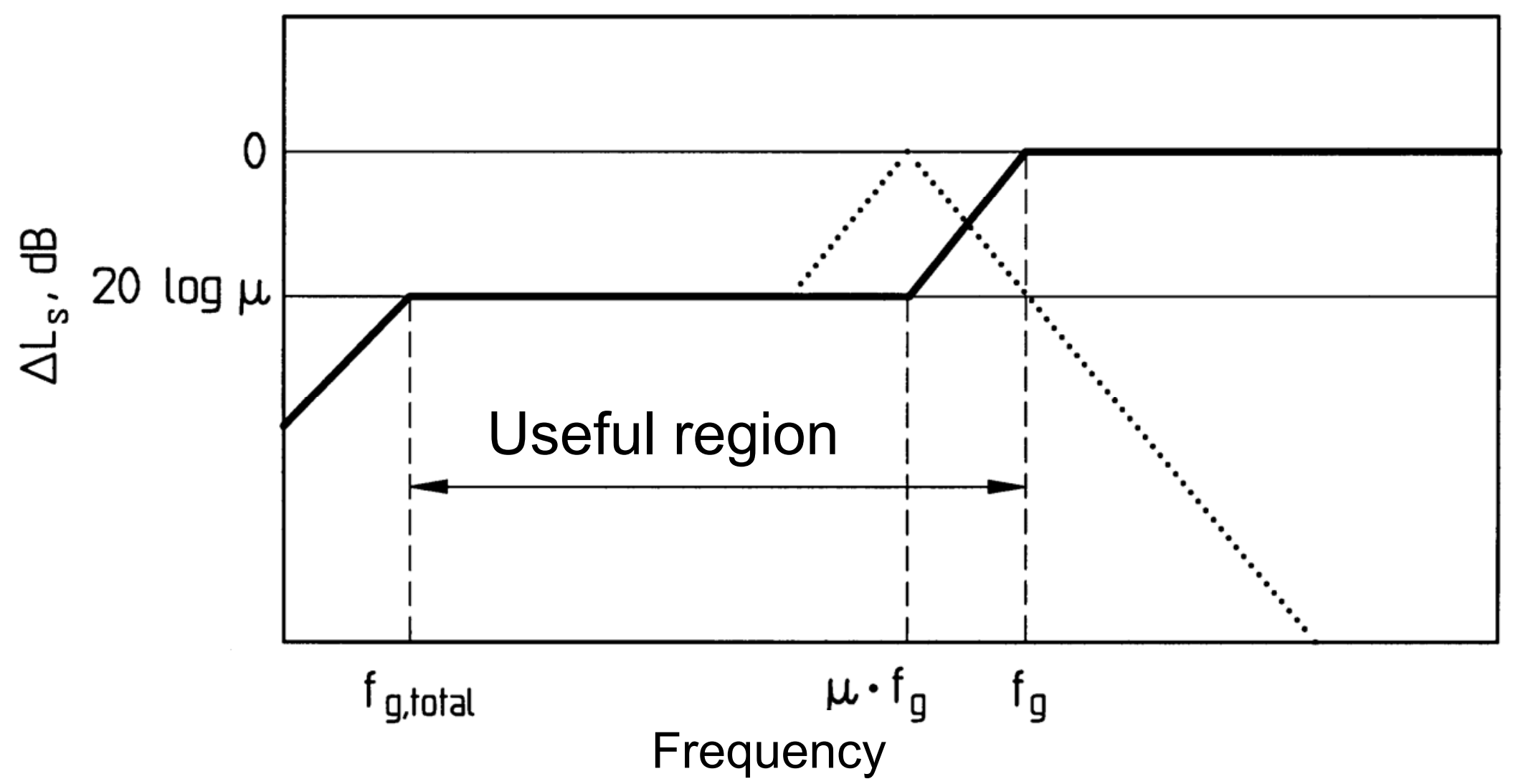

$\Delta \mathrm{L}_{\mathrm{s}}=20 \log \mu(\mathrm{dB}) \quad f_{g}=\frac{c a^{*}}{2 S \cos \theta}$ 
Design guide compared to best position

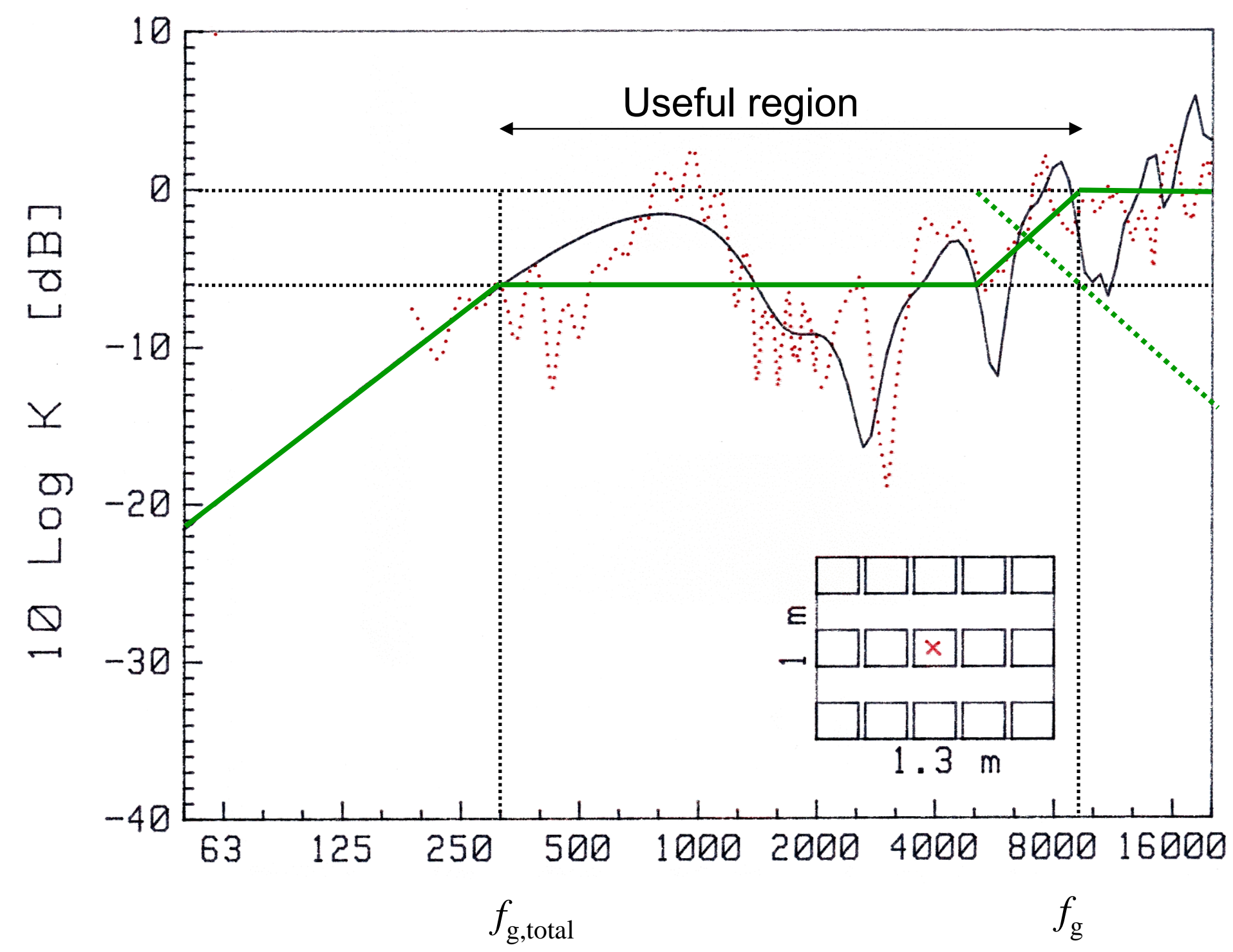


Design guide compared to worst position

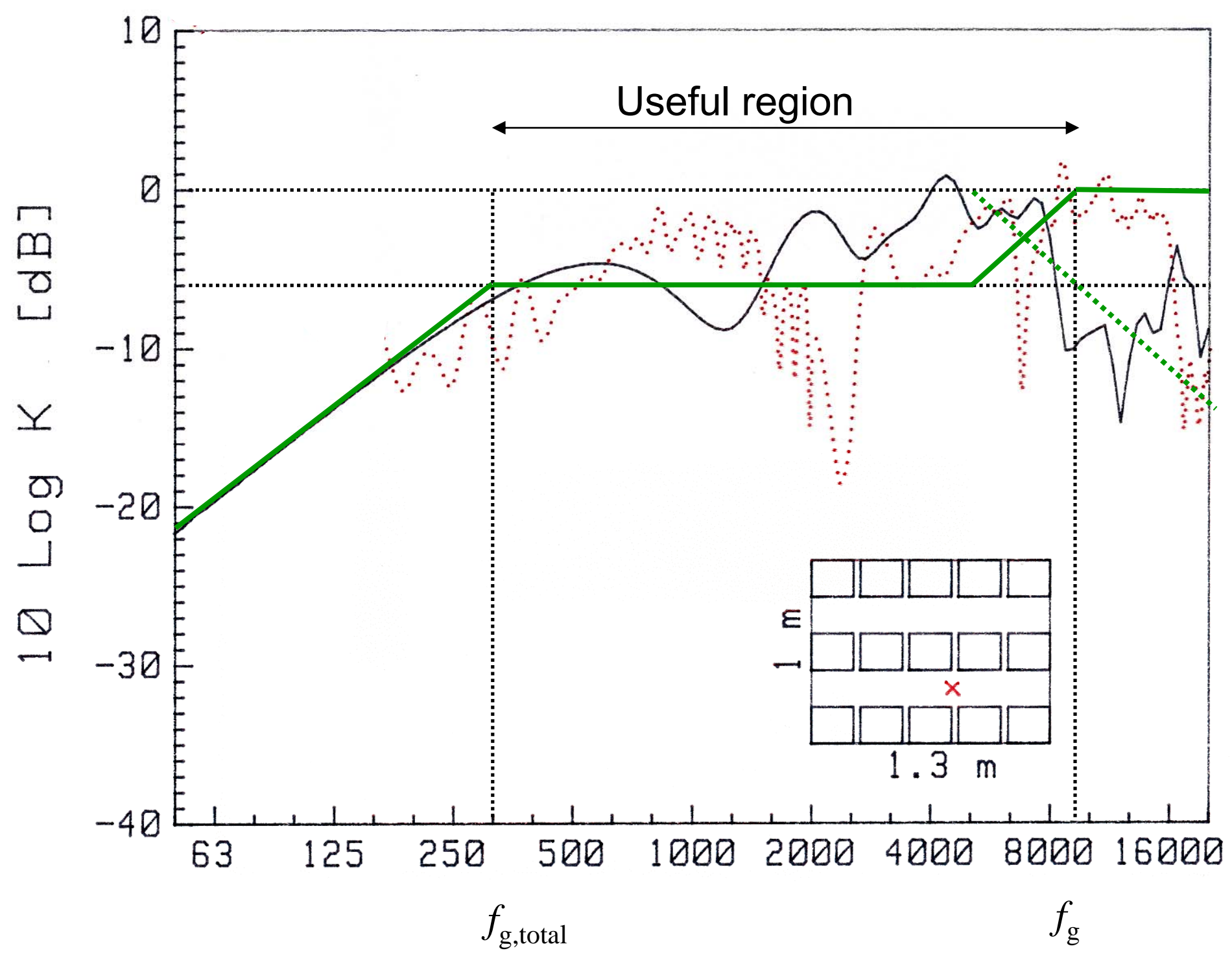




\section{Conclusion}

- The same design frequency can be used for single reflectors and reflector arrays, but with opposite meaning:

- The useful range for single a reflector is above the design frequency

- i.e. reflectors should be large

- The useful range for a reflector array is below the design frequency

- i.e. reflectors in the array should be small 


\section{Example of application}

- Danish Radio Concert Hall

- Originally from 1945, but refurbished 1989 in order to improve the acoustic conditions for the musicians on stage

- Large reflectors introduced on the side walls of the stage

- New suspended reflector array with many small plates, slightly bent to avoid gaps between rows of reflectors

1991: Design of New Ceiling Reflectors for Improved Ensemble in a Concert Hall. Applied Acoustics 34, pp. 7-17. 


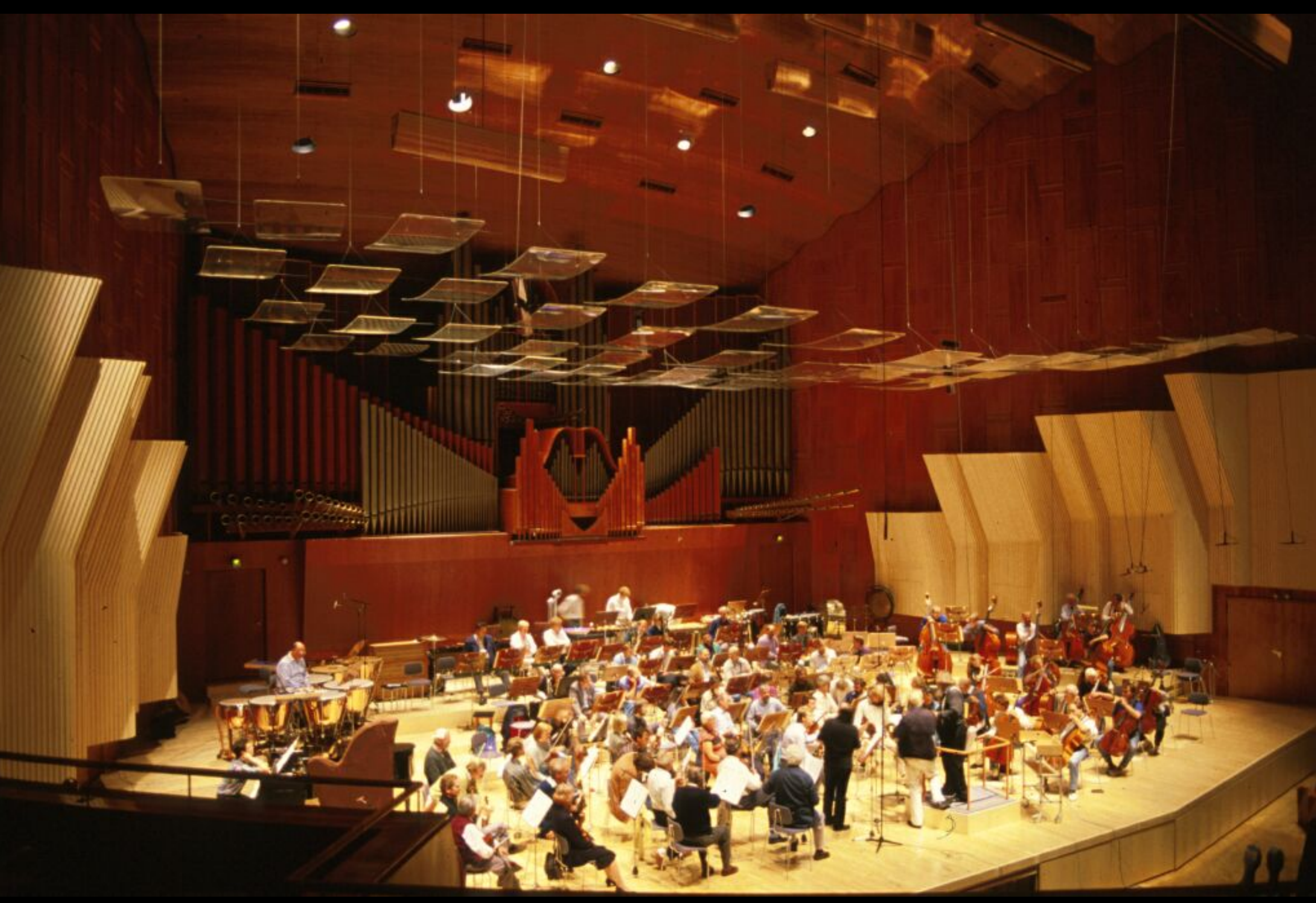

